Article

\title{
Electrochromic Devices Based on Poly(2,6-di(9H- carbazol-9-yl)pyridine)-Type Polymer Films and PEDOT-PSS
}

\author{
Chung-Wen Kuo ${ }^{1}$, Bo-Wei Wu ${ }^{1}$, Jeng-Kuei Chang ${ }^{2}{ }^{(\mathbb{D}}$, Jui-Cheng Chang ${ }^{3}$, Li-Ting Lee ${ }^{4}$, \\ Tzi-Yi Wu ${ }^{3, *(1)}$ and Tsung-Han Ho ${ }^{1}$ \\ 1 Department of Chemical and Materials Engineering, National Kaohsiung University of Science and \\ Technology, Kaohsiung 80778, Taiwan; welly@cc.kuas.edu.tw (C.-W.K.); \\ 1104311140@gm.kuas.edu.tw (B.-W.W.); thho@cc.kuas.edu.tw (T.-H.H.) \\ 2 Institute of Materials Science and Engineering, National Central University, Taoyuan 32001, Taiwan; \\ jkchang@ncu.edu.tw \\ 3 Department of Chemical Engineering and Materials Engineering, National Yunlin University of Science and \\ Technology, Yunlin 64002, Taiwan; d700215@gmail.com \\ 4 Department of Materials Science and Engineering, Feng Chia University, Taichung 40724, Taiwan; \\ ltlee@fcu.edu.tw \\ * Correspondence: wuty@gemail.yuntech.edu.tw; Tel.: +886-5-534-2601 (ext. 4626)
}

Received: 21 April 2018; Accepted: 29 May 2018; Published: 31 May 2018

\begin{abstract}
Di(9H-carbazol-9-yl)pyridine (DiCP) was synthesized and its corresponding homopolymer (PDiCP) and copolymers (P(DiCP-co-CPDT), P(DiCP-co-CPDT2), P(DiCP-co-CPDTK), and $\mathrm{P}(\mathrm{DiCP}-\mathrm{co}-\mathrm{CPDTK} 2)$ ) were synthesized electrochemically. The anodic copolymer with DiCP:cyclopentadithiophene ketone $($ CPDTK) $=1: 1$ feed molar ratio showed high transmittance change $(\Delta T \%)$ and colouration efficiency $(\eta)$, which were measured as $39.5 \%$ and $184.1 \mathrm{~cm}^{2} \mathrm{C}^{-1}$ at $1037 \mathrm{~nm}$, respectively. Electrochromic devices (ECDs) were composed of PDiCP, P(DiCP-co-CPDT), P(DiCP-co-CPDT2), P(DiCP-co-CPDTK), and P(DiCP-co-CPDTK2) as anodically-colouring polymers, and poly(3,4-ethylenedioxythiophene)-poly(styrene sulfonic acid) (PEDOT-PSS) as cathodically-colouring polymers. P(DiCP-co-CPDTK)/PEDOT-PSS ECD showed light silverish-yellow at $0.0 \mathrm{~V}$, light grey at $0.7 \mathrm{~V}$, grey at $1.3 \mathrm{~V}$, light greyish blue at $1.7 \mathrm{~V}$, and greyish blue at $2.0 \mathrm{~V}$. Moreover, $\mathrm{P}(\mathrm{DiCP}$-co-CPDTK)/PEDOT-PSS ECD presented high $\Delta T(38.2 \%)$ and high $\eta$ $\left(633.8 \mathrm{~cm}^{2} \mathrm{C}^{-1}\right)$ at $635 \mathrm{~nm}$.
\end{abstract}

Keywords: electrochromic polymer; spectroelectrochemistry; electrochemical polymerization; optical contrast; poly(3,4-ethylenedioxythiophene)-poly(styrene sulfonic acid)

\section{Introduction}

Organic electroactive materials (OEM) have played a role in science and commercial electronic devices due to their benefits of facile processing, flexibility of molecular design and synthesis, and reversibility between oxidation and reduction processes [1]. Conjugated polymers (CPs) were widely-studied organic electroactive materials due to their potential applications in supercapacitors [2], light-emitting diodes [3-5], electrochromic devices (ECDs) [6-8], solar cells [9,10], fluorescent sensors [11,12], catalysts for methanol electroxidation [13-15], and organic transistors [16]. Among these applications, scientists have focused immensely in ECDs by virtue of their multicolour and energy-saving characteristics after applying a voltage [17].

During the last decade, several CPs, such as polythiophenes (PTh) [18], polycarbazoles (PCz) [19,20], polytriphenylamines [21,22], polyanilines (PANI) [23], polyindoles [24,25], 
polyazulenes [26], and polyimides [27] have been widely studied for use as electrochromic materials. Among these CPs, PCz showed a light colour in the neutral state and a deep colour in oxidized state. Carbazole derivatives can be functionalized at the 9-,3,6-, and 2,7-positions and a wide variation of alkyl and phenyl chains can be incorporated at the 9-,3,6-, and 2,7-positions of carbazole derivatives. Metin et al. synthesized a star-shaped compound (2,4,6-tris((9H-carbazol-2-yl)oxy)-1,3,5-triazine (CTR)) and reported that $\mathrm{P}(\mathrm{CTR})$ switches between dark turquoise and transparent with an optical contrast of $50 \%$, the $\Delta T$ of $\mathrm{P}(\mathrm{CTR}) / \mathrm{P}(\mathrm{EDOT}) \mathrm{ECD}$ was measured as $32 \%$ at $615 \mathrm{~nm}$ [28]. Zhang et al. reported that a multichromic copolymer (P(CDPN-co-EDOT)) revealed claret red, green, cadet blue, and blue from neutral to oxidized states. $\mathrm{P}(\mathrm{CDPN}-\mathrm{co}$-EDOT) film showed $\Delta T$ of $36 \%$ in the visible region and a $\Delta T$ of $43 \%$ in the near-infrared region [29]. PTh and their derivatives were usually employed to diminish the band gap and improve the conjugation of the polymer backbone. The derivatives of PTh (poly(3,4-ethylenedioxythiophene)s (PEDOT) and poly(3,4-(2,2-dimethylpropylenedioxy)thiophene)s (PProDOT-Me $\left.\mathrm{M}_{2}\right)$ comprised two electron-donating oxygen atoms at 3,4-positions of thiophene ring, which diminished the onset potentials of oxidation for polymer films and diminished the band gaps of polymer films. Moreover, PEDOT and PProDOT-Me 2 showed high transmissivity in the doped state and low transmissivity in the undoped state, which made PEDOT and PProDOT-Me 2 promising candidates for use as cathodic electrodes in electrochromic devices [30]. Furthermore, copolymerization is an efficient and promising way to improve electrochromic properties of the CPs. Copolymerization of dissimilar monomers containing numerous distinct units can bring about interesting combinations of the electrochromic characteristics. For this affair, copolymers based on carbazole and bithiophene derivatives are copolymerized in the study. 2,6-di(9H-carbazol-9-yl)pyridine comprises two carbazole groups linked by a pyridine ring, the carbazole and pyridine groups are electron-donating and electron-withdrawing groups, respectively. Cyclopentadithiophene ketone (CPDTK) comprises two thiophene rings linked by a single bond and a carbonyl group at the 2-position and 3-position of thiophene rings, respectively, the thiophene and carbonyl groups are electron-donating and electron-withdrawing groups, respectively. Electrochromic polymers based on monomers possessing donor-acceptor-donor (D-A-D) units can adjust the colour in their doped and dedoped states and the colour of dual type electrochromic devices at various voltages.

Up to now, the incorporation of a 2,6-di(9H-carbazol-9-yl)pyridine unit into electrochromic polymer backbones and the electrochromic behaviors of poly(2,6-di(9H-carbazol-9-yl)pyridine)s at various potentials have not been reported. In the present work, 2,6-di(9H-carbazol-9-yl)pyridine $(\mathrm{DiCP})$ is synthesized and its corresponding homopolymer (PDiCP) and copolymers (P(DiCP-co-CPDT), P(DiCP-co-CPDT2), P(DiCP-co-CPDTK), and P(DiCP-co-CPDTK2)) are synthesized using electrochemical copolymerization. The spectroelectrochemical behaviours of PDiCP, P(DiCP-co-CPDT), P(DiCP-co-CPDT2), P(DiCP-co-CPDTK), and P(DiCP-co-CPDTK2) films at various potentials are comprehensively studied. It is interesting to explore that the slight structural modifications of the bithiophene derivatives give rise to diverse spectroelectrochemical behaviours. Moreover, five ECDs were fabricated using PDiCP, $\mathrm{P}(\mathrm{DiCP}-\mathrm{co}-\mathrm{CPDT}), \mathrm{P}(\mathrm{DiCP}-\mathrm{co}-\mathrm{CPDT} 2), \mathrm{P}(\mathrm{DiCP}-\mathrm{co}-\mathrm{CPDTK})$, and $\mathrm{P}(\mathrm{DiCP}-\mathrm{co}-\mathrm{CPDTK} 2)$ films as the anodically-colouring polymers, poly(3,4-ethylenedioxythiophene)-poly(styrene sulfonic acid) (PEDOT-PSS) as the cathodically-colouring polymer. The optical contrast, colouration efficiency, switching property, optical memory, and redox stability of the five ECDs were also studied.

\section{Materials and Methods}

\subsection{Materials}

2,6-dibromopyridine, carbazole, and PEDOT-PSS (1.3 wt \% dispersion in water) were purchased from Aldrich (St. Louis, MO, USA). 4H-cyclopenta[2,1-b:3,4-b']dithiophene (CPDT) and cyclopentadithiophene ketone were purchased from Tokyo Chemical (Tokyo, Japan), PMMA $\left(M_{\mathrm{W}}=350,000\right), \mathrm{LiClO}_{4}$, and propylene carbonate were purchased from Acros organics (Geel, Belgium), 
Aldrich (St. Louis, MO, USA), and Alfa Aesar (Haverhill, MA, USA), respectively, and were used as received.

\subsection{Synthesis of 2,6-di(9H-carbazol-9-yl)pyridine (DiCP)}

2,6-dibromopyridine ( $3.55 \mathrm{~g}, 15 \mathrm{mmol})$, carbazole (10.03 g, $60 \mathrm{mmol}), \mathrm{K}_{2} \mathrm{CO}_{3}(8.29 \mathrm{~g}, 60 \mathrm{mmol})$, $\mathrm{Cu}$ powder $(2.41 \mathrm{~g}, 38 \mathrm{mmol})$, and $30 \mathrm{~mL}$ triethylene glycol dimethyl ether were added in a two-neck round-bottom flask and stirred at $175{ }^{\circ} \mathrm{C}$ for $48 \mathrm{~h}$. Triethylene glycol dimethyl ether was vaporized using a rotavapor under reduced pressure, and the crude product was purified through column chromatography (silica gel with an eluent of dichloromethane/hexane mixture). Recrystallization from toluene to give desired DiCP. Yield: $62 \% .{ }^{1} \mathrm{H}$ NMR $\left(700 \mathrm{MHz}, \mathrm{DMSO}-d_{6}\right): \delta 8.42(\mathrm{dd}, 1 \mathrm{H}$, pyridine-H), $8.28(\mathrm{~d}, 4 \mathrm{H}$, carbazole-H), $7.93(\mathrm{~d}, 4 \mathrm{H}$, carbazole-H), $7.88(\mathrm{~d}, 2 \mathrm{H}$, pyridine- $\mathrm{H}), 7.45$ (dd, $4 \mathrm{H}$, carbazole-H), 7.35 (dd, $4 \mathrm{H}$, carbazole-H). Elem. Anal. Calcd. for $\mathrm{C}_{29} \mathrm{H}_{19} \mathrm{~N}_{3}: \mathrm{C}, 85.06 \% ; \mathrm{H}, 4.68 \%$;, $10.26 \%$. Found: C, $84.95 \% ; \mathrm{H}, 4.59 \% ; \mathrm{N}, 10.21 \%$.

2.3. Electrochemical Polymerization of PDiCP, P(DiCP-co-CPDT), P(DiCP-co-CPDT2), P(DiCP-co-CPDTK), and P(DiCP-co-CPDTK2) Films

PDiCP, P(DiCP-co-CPDT), P(DiCP-co-CPDT2), P(DiCP-co-CPDTK), and P(DiCP-co-CPDTK2) films were electrosynthesized using cyclic voltammetry $(\mathrm{CV})$ between 0.0 and $1.5 \mathrm{~V}$ with a scan rate of $100 \mathrm{mV} \mathrm{s}^{-1}$ in an acetonitrile (ACN)/dichloromethane (DCM) (1:1, by volume) solution containing $0.2 \mathrm{M} \mathrm{LiClO}_{4}$ as an electrolyte, the feed species and molar ratio of anodically-colouring polymers are presented in Table 1. The counter and reference electrodes of the electrochemical system are a platinum wire and an $\mathrm{Ag} / \mathrm{AgCl}(3 \mathrm{M} \mathrm{KCl})$ electrode, respectively. The cathodic PEDOT-PSS film is prepared using spin-coating methods, and the spin condition for preparing PEDOT-PSS film is $2000 \mathrm{rpm}$. The active area of polymer electrode is $1.0 \mathrm{~cm} \times 1.5 \mathrm{~cm}$. The electrochemical polymerization schemes of PDiCP, P(DiCP-co-CPDT), and P(DiCP-co-CPDTK) are shown in Figure 1.

Table 1. Feed species of anodically-colouring polymers (a)-(e).

\begin{tabular}{cccc}
\hline Electrodes & $\begin{array}{c}\text { Anodically Colouring } \\
\text { Polymers }\end{array}$ & $\begin{array}{c}\text { Feed Species of Anodic } \\
\text { Polymer }\end{array}$ & $\begin{array}{c}\text { Feed Molar Ratio of } \\
\text { Anodic Polymer }\end{array}$ \\
\hline (a) & PDiCP & $4 \mathrm{mM} \mathrm{DiCP}$ & $\mathrm{DiCP}$ \\
$(\mathrm{b})$ & $\mathrm{P}(\mathrm{DiCP}-c o-C P D T)$ & $2 \mathrm{mM} \mathrm{DiCP}+2 \mathrm{mM}$ CPDT & DiCP:CPDT $=1: 1$ \\
$(\mathrm{c})$ & $\mathrm{P}(\mathrm{DiCP}-c o-C P D T 2)$ & $2 \mathrm{mM} \mathrm{DiCP}+4 \mathrm{mM}$ CPDT & $\mathrm{DiCP}: \mathrm{CPDT}=1: 2$ \\
$(\mathrm{~d})$ & $\mathrm{P}(\mathrm{DiCP}-\mathrm{co}-\mathrm{CPDTK})$ & $2 \mathrm{mM} \mathrm{DiCP}+2 \mathrm{mM}$ CPDTK & DiCP:CPDTK $=1: 1$ \\
$(\mathrm{e})$ & $\mathrm{P}(\mathrm{DiCP}-c o-C P D T K 2)$ & $2 \mathrm{mM} \mathrm{DiCP}+4 \mathrm{mM}$ CPDTK & DiCP:CPDTK $=1: 2$ \\
\hline
\end{tabular}<smiles>c1cc(-n2c3ccccc3c3ccccc32)nc(-n2c3ccccc3c3ccccc32)c1</smiles>

electrochemical polymerization<smiles>Cc1ccc2c(c1)c1ccccc1n2-c1cccc(-n2c3ccccc3c3ccccc32)n1</smiles><smiles>c1ccc(-n2c3ccccc3c3ccccc32)cc1</smiles><smiles>c1cc2c(s1)-c1sccc1C2</smiles>

electrochemical polymerization

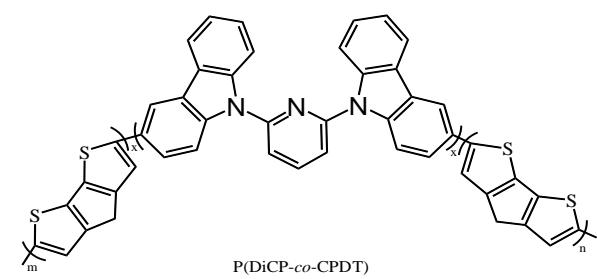

Figure 1. Cont. 

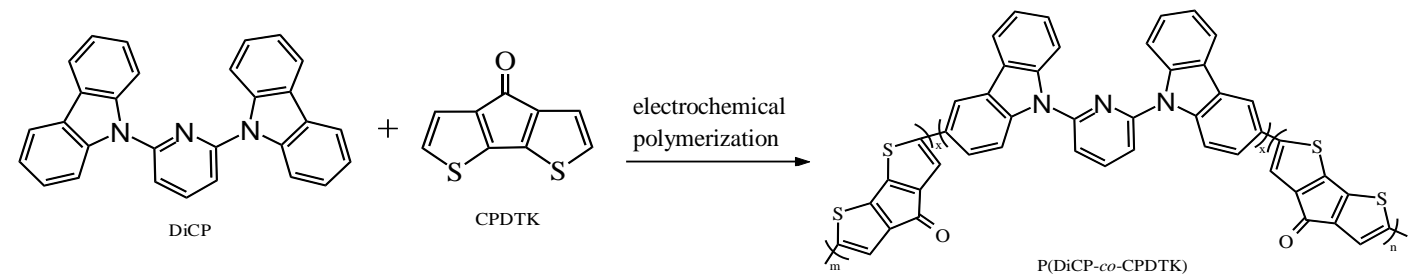

Figure 1. The electrochemical polymerization schemes of PDiCP, P(DiCP-co-CPDT), and P(DiCP-co-CPDTK).

\subsection{Preparation of Dual-Type Electrochromic Devices}

The electrolyte consisting of $\mathrm{PMMA}, \mathrm{LiClO}_{4}, \mathrm{PC}$, and $\mathrm{ACN}$ was prepared according to previously published work [31], and the electrolyte was coated on anodic PDiCP, P(DiCP-co-CPDT), P(DiCP-co-CPDT2), P(DiCP-co-CPDTK), and P(DiCP-co-CPDTK2) films. Eventually, the cathodic PEDOT-PSS film was placed onto the electrolyte to fabricate electrochromic devices.

\subsection{Electrochemical and Electrochromic Characterization}

The electrochemical characterizations of polymer films were carried out in three-component cells. An ITO coated glass, $\mathrm{Pt}$ wire, and $\mathrm{Ag} / \mathrm{AgCl}(3 \mathrm{M} \mathrm{KCl})$ electrode were used as working, counter, and reference electrodes, respectively. The electrochromic experiments and double potential chronoamperometry were implemented with a Hitachi spectrophotometer and a CHI627D $(\mathrm{CH}$ Instruments, Austin, TX, USA) electrochemical analyser.

\section{Results and Discussion}

\subsection{Electrochemical Polymerizations}

The electrooxidation of $\mathrm{DiCP}, \mathrm{CPDTK}$, and CPDT in $0.2 \mathrm{M} \mathrm{LiClO}_{4} \mathrm{ACN} / \mathrm{DCM}$ solution were shown in Figure 2. The onset potential of oxidation for DiCP, CPDT, and CPDTK were 1.15, 0.95, and $1.10 \mathrm{~V}$, respectively. The onset potential of CPDT is smaller than that of CPDTK, this can be attributed to the withdrawing keto groups of CPDTK increasing the onset potential significantly. Moreover, the differences between onset potential of oxidation for DiCP vs. CPDTK and DiCP vs. CPDT are less than $0.2 \mathrm{~V}$, indicating the copolymerizations of DiCP with CPDTK (or CPDT) are practicable. Figure 3 shows the electrochemical synthesis of PDiCP, P(DiCP-co-CPDT), P(DiCP-co-CPDT2), $\mathrm{P}$ (DiCP-co-CPDTK), and P(DiCP-co-CPDTK2) in $0.2 \mathrm{M} \mathrm{LiClO}_{4} / \mathrm{ACN} / \mathrm{DCM}$ solution (ACN:DCM = 1:1, by volume) at $100 \mathrm{mV} \mathrm{s}^{-1}$ on ITO working electrode.

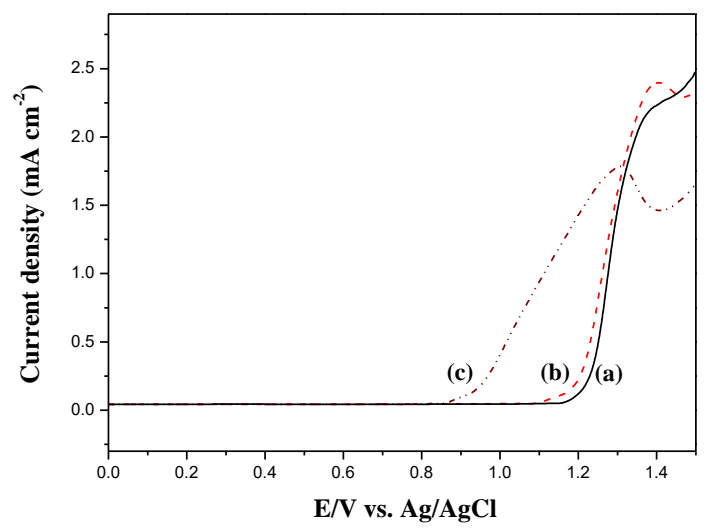

Figure 2. Electrooxidation of (a) $4 \mathrm{mM}$ DiCP; (b) $4 \mathrm{mM} \mathrm{CPDTK}$; and (c) $4 \mathrm{mM} \mathrm{CPDT}$ in $0.2 \mathrm{M} \mathrm{LiClO}_{4}$ containing ACN/DCM (1:1, by volume) solution at a scan rate of $100 \mathrm{mV} \mathrm{s}^{-1}$. 

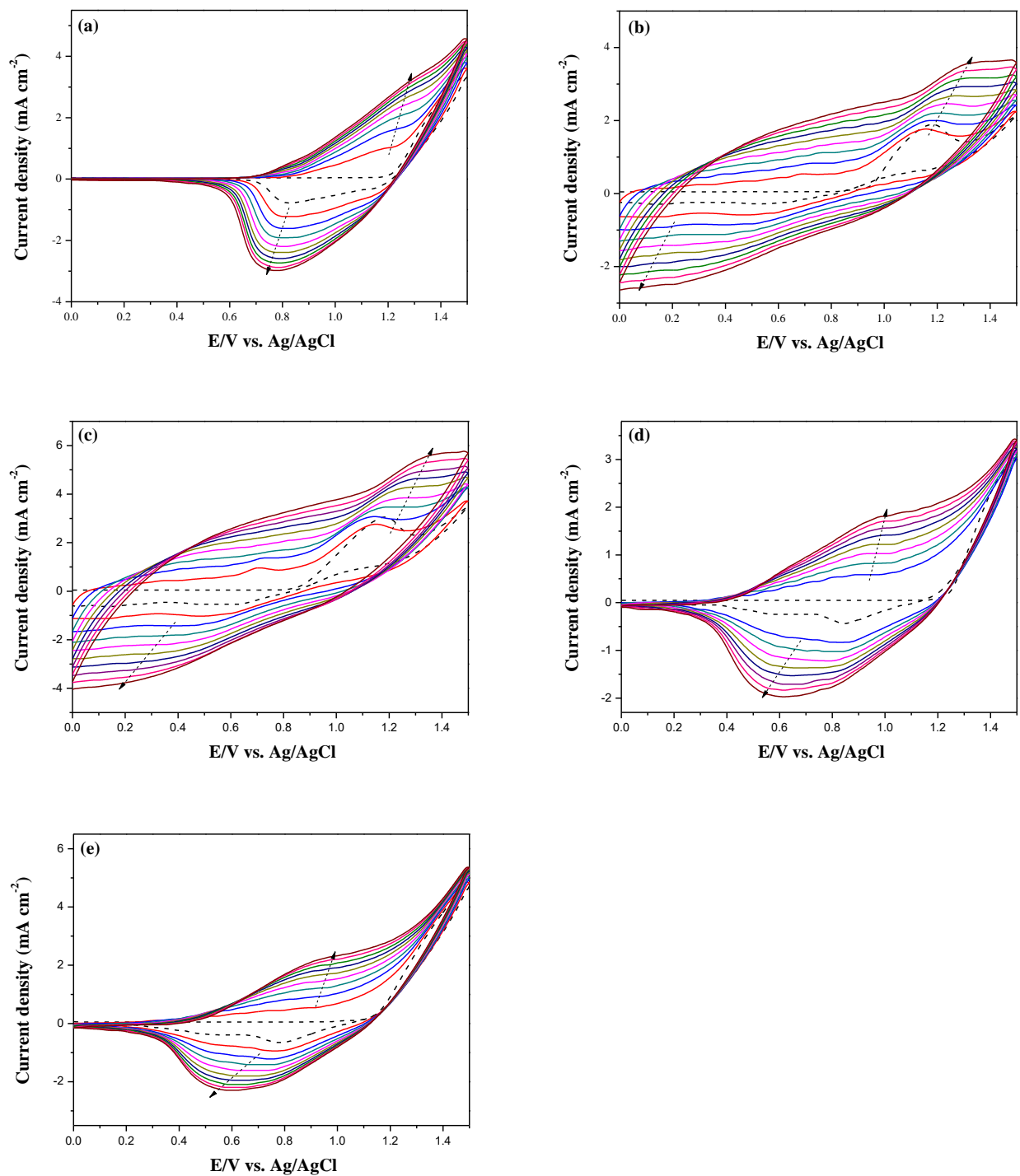

Figure 3. Electrochemical synthesis of (a) PDiCP; (b) P(DiCP-co-CPDT); (c) P(DiCP-co-CPDT2); (d) $\mathrm{P}(\mathrm{DiCP}-\mathrm{co}$-CPDTK); and (e) $\mathrm{P}(\mathrm{DiCP}-\mathrm{co}-\mathrm{CPDTK} 2)$ in ACN/DCM (1:1, by volume) solution at $100 \mathrm{mV}$ $\mathrm{s}^{-1}$ on the ITO working electrode.

The current densities of the redox peaks increase with increasing scanning CV cycles, implying both deposition of the polymer films and that the deposited polymers are conducting [32]. The oxidation peaks of PDiCP, P(DiCP-co-CPDT), P(DiCP-co-CPDT2), P(DiCP-co-CPDTK), and $\mathrm{P}(\mathrm{DiCP}-\mathrm{co}-\mathrm{CPDTK} 2)$ located at $1.15,1.10,1.10,0.9$ and $0.9 \mathrm{~V}$, respectively, whereas the reduction peaks of PDiCP, P(DiCP-co-CPDT), P(DiCP-co-CPDT2), P(DiCP-co-CPDTK), and P(DiCP-co-CPDTK2) located at $0.75,0.45,0.5,0.6$, and $0.6 \mathrm{~V}$, respectively. The redox peaks and $\mathrm{CV}$ curves of $\mathrm{P}(\mathrm{DiCP}-\mathrm{co}-\mathrm{CPDT}), \mathrm{P}(\mathrm{DiCP}-\mathrm{co}-\mathrm{CPDT} 2), \mathrm{P}(\mathrm{DiCP}-\mathrm{co}-\mathrm{CPDTK})$, and $\mathrm{P}(\mathrm{DiCP}-\mathrm{co}-\mathrm{CPDTK} 2)$ are different from the oxidation and reduction peaks and $\mathrm{CV}$ curves of $\mathrm{PDiCP}$, indicating the formation of $\mathrm{P}(\mathrm{DiCP}-c o-\mathrm{CPDT}), \mathrm{P}(\mathrm{DiCP}-\mathrm{co}-\mathrm{CPDT} 2), \mathrm{P}(\mathrm{DiCP}-c o-\mathrm{CPDTK})$, and $\mathrm{P}(\mathrm{DiCP}-c o-\mathrm{CPDTK} 2)$ films on ITO electrodes. Specific capacitances of PDiCP, P(DiCP-co-CPDT), P(DiCP-co-CPDT2), P(DiCP-co-CPDTK), and $\mathrm{P}(\mathrm{DiCP}-\mathrm{co}-\mathrm{CPDTK} 2)$ electrodes are $76,92,94,85$, and $88 \mathrm{~F} / \mathrm{g}$, respectively.

Figure 4 shows the $\mathrm{CV}$ curves of deposited P(DiCP-co-CPDTK) film at 10, 50, 100, 150, and $200 \mathrm{mV} \mathrm{s}^{-1}$ in $0.2 \mathrm{M} \mathrm{LiClO}_{4} / \mathrm{ACN} / \mathrm{DCM}$ solution, the P(DiCP-co-CPDTK) film shows well-defined redox peaks at various scan rates and the anodic and cathodic peak current densities are 
proportional to the scan rates (inset of Figure 4), inferring the P(DiCP-co-CPDTK) film was stuck onto ITO glass and the redox process of the copolymer film was not diffusional control [33].

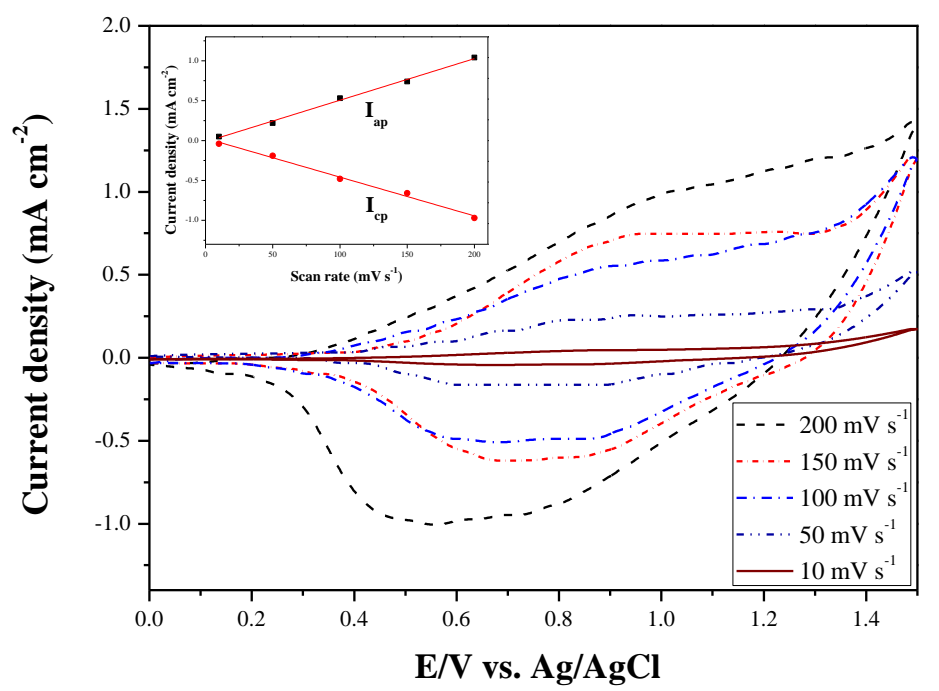

Figure 4. $\mathrm{CV}$ curves of the $\mathrm{P}\left(\mathrm{DiCP}-\mathrm{co}\right.$-CPDTK) films at different scan rates between 10 and $200 \mathrm{mV} \mathrm{s}^{-1}$ in $0.2 \mathrm{M} \mathrm{LiClO}_{4} / \mathrm{ACN} / \mathrm{DCM}$ solution. Scan rate dependence of the anodic and cathodic peak current densities for $\mathrm{P}(\mathrm{DiCP}-\mathrm{co}-\mathrm{CPDTK})$ films (inset).

\subsection{Spectroelectrochemical Characterizations of Homopolymer and Copolymer Films}

Figure 5 shows the spectroelectrochemical spectra of PDiCP, P(DiCP-co-CPDT), P(DiCP-co-CPDT2), $\mathrm{P}(\mathrm{DiCP}-\mathrm{co}-\mathrm{CPDTK})$, and $\mathrm{P}(\mathrm{DiCP}-\mathrm{co}-\mathrm{CPDTK} 2)$ films at various potentials in $0.2 \mathrm{M} \mathrm{LiClO}_{4} / \mathrm{ACN} / \mathrm{DCM}$ solution, and that there is no prominent absorption peak of PDiCP film at $0.0 \mathrm{~V}$.

Upon increasing the potential progressively, new bands appeared at 425 and $1000 \mathrm{~nm}$, which could be assigned to the formation of charge carriers for PDiCP film [34]. However, P(DiCP-co-CPDT), P(DiCP-co-CPDT2), P(DiCP-co-CPDTK), and P(DiCP-co-CPDTK2) films showed $\pi-\pi^{*}$ (or $\mathrm{n}-\pi^{*}$ ) transition peaks at $485,500,392$, and $395 \mathrm{~nm}$, respectively, which were different to the absorption spectra of PDiCP film in the neutral state. The UV-VIS spectra of P(DiCP-co-CPDT) film recorded for various potentials exhibit isosbestic points, suggesting the presence of neutral and oxidized $\mathrm{P}(\mathrm{DiCP}-\mathrm{co}-\mathrm{CPDT})$ films which are active towards different irradiations at different potentials. The charge carrier bands of $\mathrm{P}(\mathrm{DiCP}-\mathrm{co}-\mathrm{CPDT}), \mathrm{P}(\mathrm{DiCP}-\mathrm{co}-\mathrm{CPDT} 2), \mathrm{P}(\mathrm{DiCP}-\mathrm{co}-\mathrm{CPDTK})$, and $\mathrm{P}\left(\mathrm{DiCP}-\mathrm{co}\right.$-CPDTK2) films in $0.2 \mathrm{M} \mathrm{LiClO}_{4} / \mathrm{ACN} / \mathrm{DCM}$ solution showed significant variations at $1000 \mathrm{~nm}$ from neutral to oxidation states.

The PDiCP film showed three kinds of colour variations from neutral to oxidation state, PDiCP film was light gray at $0.0 \mathrm{~V}$, dark khaki at $1.0 \mathrm{~V}$, and grey black at $1.2 \mathrm{~V}$. For the copolymer films,

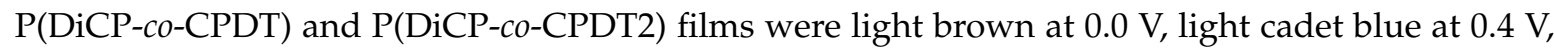
and navy blue at 1.1 (or $1.3 \mathrm{~V}$ ), whereas $\mathrm{P}(\mathrm{DiCP}-\mathrm{co}$-CPDTK) and $\mathrm{P}(\mathrm{DiCP}-\mathrm{co}-\mathrm{CPDTK} 2)$ films were light yellow at $0.0 \mathrm{~V}$, grey at $0.8 \mathrm{~V}$, and rock grey at $1.1 \mathrm{~V}$. The colorimetric values $\left(L^{*}, a^{*}\right.$, and $\left.b^{*}\right)$ and CIE chromaticity diagrams of PDiCP, P(DiCP-co-CPDT2), and P(DiCP-co-CPDTK) films at various potentials are displayed in Table 2. 

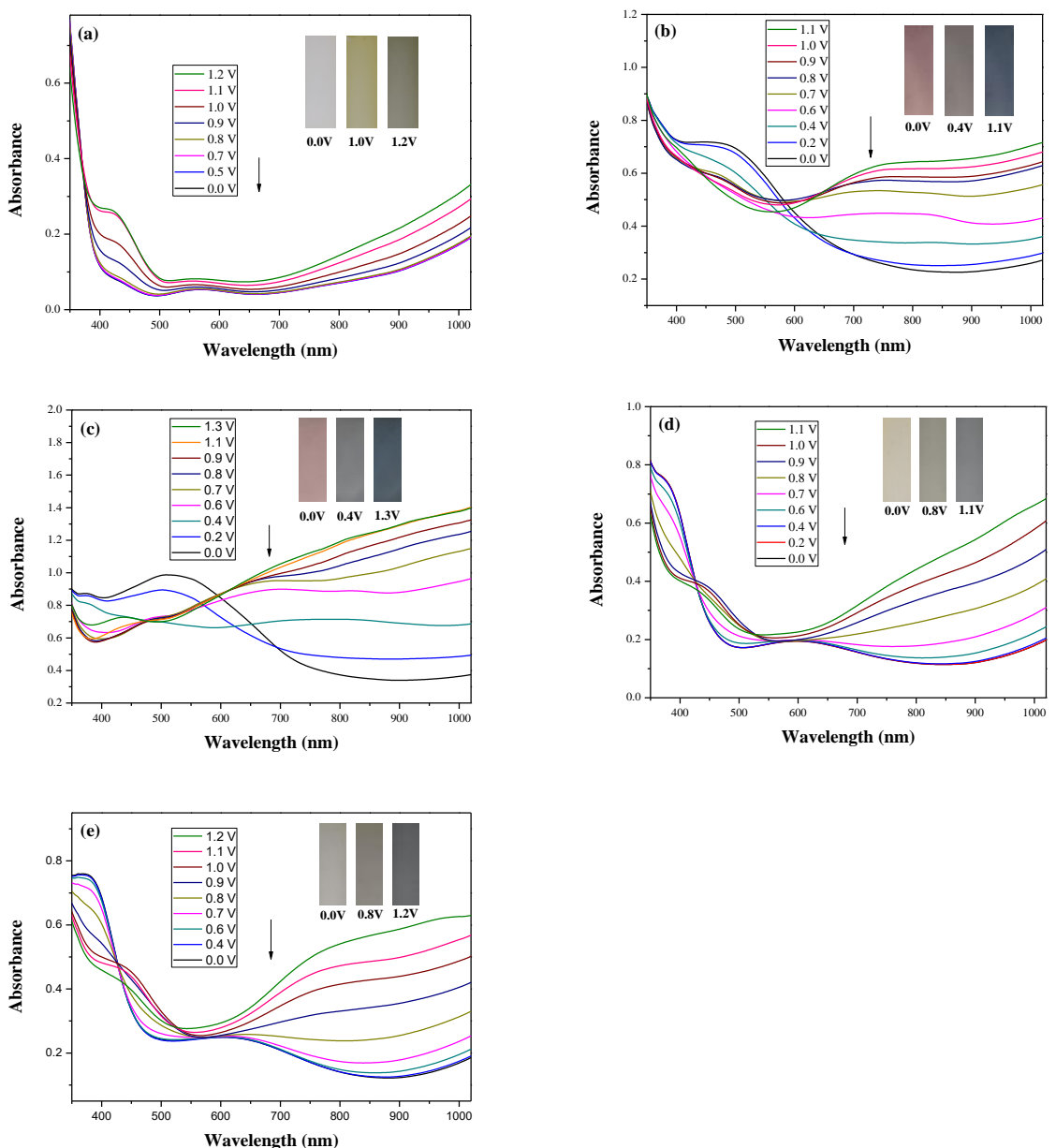

Figure 5. UV-VIS spectra of (a) PDiCP; (b) P(DiCP-co-CPDT); (c) P(DiCP-co-CPDT2); (d) P(DiCP-co-CPDTK); and (e) P(DiCP-co-CPDTK2) electrodes on ITO in $0.2 \mathrm{M} \mathrm{LiClO}_{4}$ containing ACN/DCM (1:1, by volume) solution.

Table 2. Colorimetric values $\left(L^{*}, a^{*}\right.$, and $\left.b^{*}\right)$, CIE chromaticity values $(x, y)$, and CIE diagrams of (a) PDiCP, (b) P(DiCP-co-CPDT2), and (c) P(DiCP-co-CPDTK) films at various applied potentials.

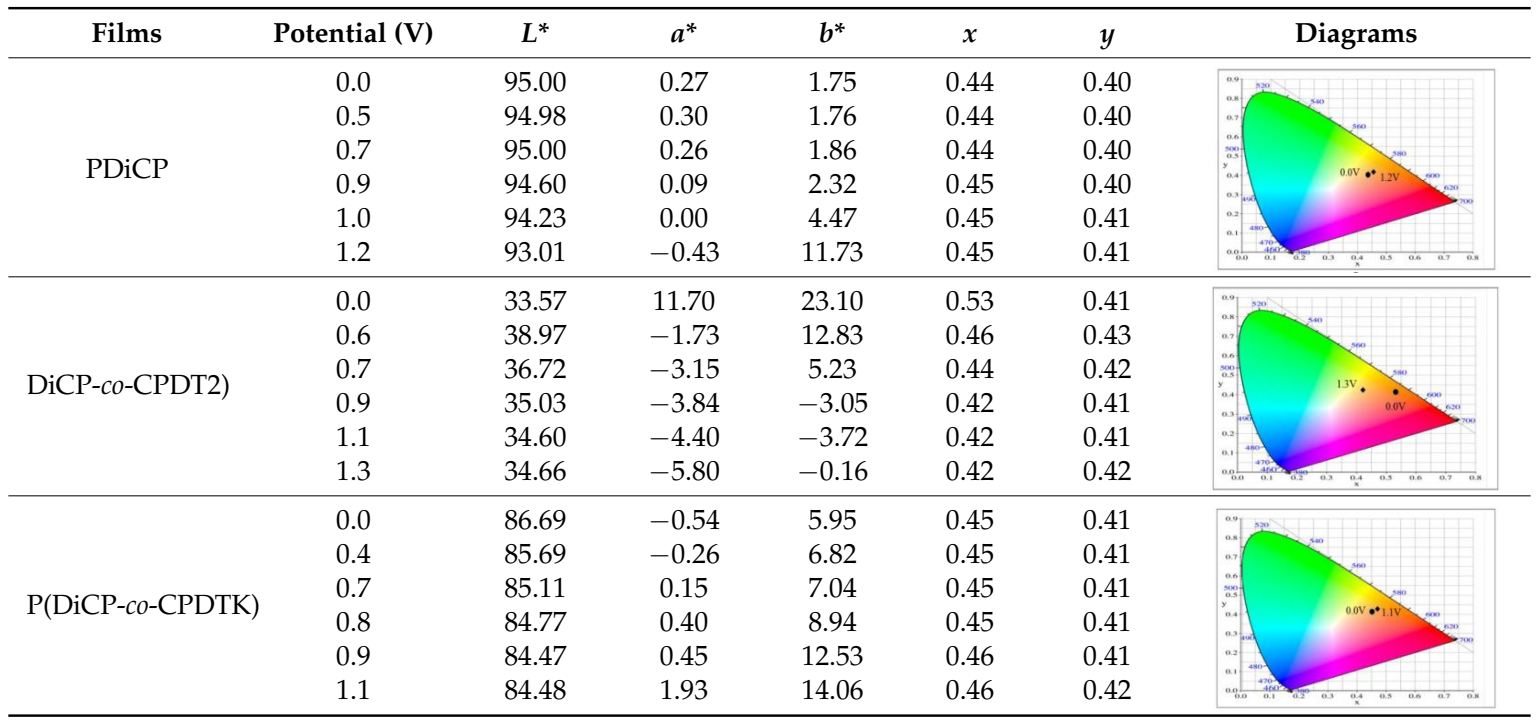


The optical band gap $\left(E_{\mathrm{g}}\right)$ of PDiCP homopolymer film calculated using Planck equation was $2.58 \mathrm{eV}$ :

$$
E_{\mathrm{g}}=1241 / \lambda_{\text {onset }}
$$

where the onset UV absorption wavelength $\left(\lambda_{\text {onset }}\right)$ of the $\pi-\pi^{*}$ transition band of PDiCP was $481 \mathrm{~nm}[35,36]$. The onset oxidation potential vs. $\mathrm{Ag} / \mathrm{AgCl}(3 \mathrm{M} \mathrm{KCl})$ was $0.82 \mathrm{~V}$, the $E_{\mathrm{FOC}}$ of ferrocene/ferrocenium vs. $\mathrm{Ag} / \mathrm{AgCl}(3 \mathrm{M} \mathrm{KCl})$ determined using cyclic voltammetry was $0.80 \mathrm{~V}$, and the onset oxidation potential vs. $E_{\mathrm{FOC}}$ was found to be $0.02 \mathrm{~V}$. The HOMO and LUMO energy levels of PDiCP determined from the onset oxidation potential with respect to the energy level of ferrocene/ferrocenium couple $\left(-4.8 \mathrm{eV}\right.$ less than vacuum energy level) $[37,38]$ and $E_{\mathrm{g}}$ were taken as -4.82 and $-2.24 \mathrm{eV}$, respectively.

Figure 6 showed the electrochromic switching profiles of PDiCP, P(DiCP-co-CPDT), $\mathrm{P}(\mathrm{DiCP}-c o-\mathrm{CPDT} 2), \mathrm{P}(\mathrm{DiCP}-c o-\mathrm{CPDTK})$, and $\mathrm{P}(\mathrm{DiCP}-c o-C P D T K 2)$ films in $0.2 \mathrm{M} \mathrm{LiClO}_{4} / \mathrm{ACN} / \mathrm{DCM}$ solution, which were monitored using double potential-step chronoamperometry by repeating potentials between 0.0 and $1.2 \mathrm{~V}$ with a time interval of $10 \mathrm{~s}$. The $\Delta T$ of PDiCP at $1025 \mathrm{~nm}$, $\mathrm{P}(\mathrm{DiCP}-\mathrm{co}-\mathrm{CPDT})$ at $1034 \mathrm{~nm}, \mathrm{P}(\mathrm{DiCP}-\mathrm{co}-\mathrm{CPDT} 2)$ at $1034 \mathrm{~nm}, \mathrm{P}(\mathrm{DiCP}-\mathrm{co}-\mathrm{CPDTK})$ at $1037 \mathrm{~nm}$, and $\mathrm{P}(\mathrm{DiCP}-\mathrm{co}-\mathrm{CPDTK} 2)$ at $890 \mathrm{~nm}$ from the bleaching state to the colouration state in $0.2 \mathrm{M}$ $\mathrm{LiClO}_{4} / \mathrm{ACN} / \mathrm{DCM}$ solution were calculated to be 18.8, 28.3, 29.1, 39.5, and 35.9\%, respectively. Among these polymer films, $\mathrm{P}(\mathrm{DiCP}-c o-\mathrm{CPDTK})$ film presents the highest $\Delta T$, and copolymers (P(DiCP-co-CPDT), P(DiCP-co-CPDT2), $\mathrm{P}(\mathrm{DiCP}-\mathrm{co}-\mathrm{CPDTK})$, and $\mathrm{P}(\mathrm{DiCP}-\mathrm{co}-\mathrm{CPDTK} 2)$ ) present higher $\Delta T$ than that of homopolymer (PDiCP) in $0.2 \mathrm{M} \mathrm{LiClO}_{4} / \mathrm{ACN} / \mathrm{DCM}$ solution, implying the copolymerization of DiCP with CPDT (or CPDTK) monomer results in the increase of $\Delta T$ in $0.2 \mathrm{M}$ $\mathrm{LiClO}_{4} / \mathrm{ACN} / \mathrm{DCM}$ solution. The colouration switching time $\left(\tau_{\mathrm{c}}\right)$ and bleaching switching time $\left(\tau_{\mathrm{b}}\right)$ of polymer films in $0.2 \mathrm{M} \mathrm{LiClO}_{4} / \mathrm{ACN} / \mathrm{DCM}$ solution are listed in Table 3 , the $\tau_{\mathrm{c}}$ and $\tau_{\mathrm{b}}$ are determined at $90 \%$ of the whole transmittance change. The $\tau_{\mathrm{c}}$ and $\tau_{\mathrm{b}}$ of PDiCP, P(DiCP-co-CPDT), $\mathrm{P}$ (DiCP-co-CPDT2), P(DiCP-co-CPDTK), and P(DiCP-co-CPDTK2) films in 0.2 $\mathrm{M} \mathrm{LiClO}_{4} / \mathrm{ACN} / \mathrm{DCM}$ solution are in the range of $1.9-6.7 \mathrm{~s}$.

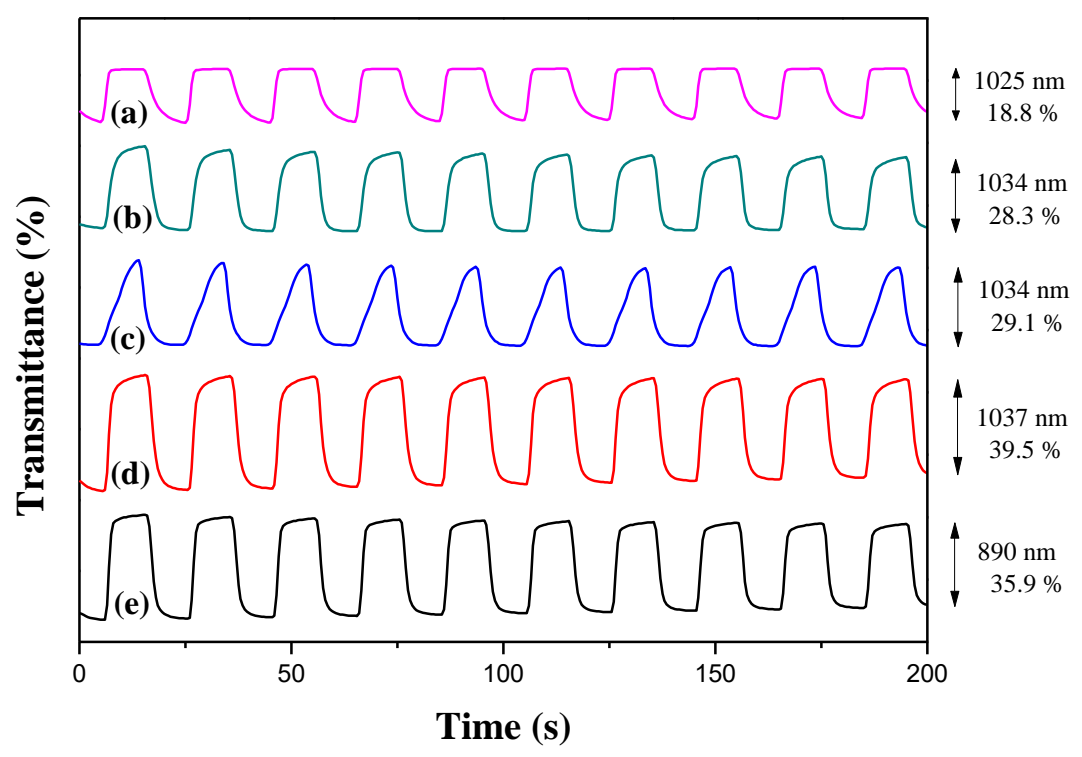

Figure 6. Transmittance changes of (a) PDiCP; (b) P(DiCP-co-CPDT); (c) P(DiCP-co-CPDT2); (d) $\mathrm{P}$ (DiCP-co-CPDTK); and (e) $\mathrm{P}(\mathrm{DiCP}-c o-C P D T K 2)$ electrodes in a $0.2 \mathrm{M} \mathrm{LiClO}_{4}$ containing ACN/DCM (1:1, by volume) solution. 
Table 3. Optical and electrochemical properties investigated at the selected applied wavelength for the electrodes.

\begin{tabular}{cccccccccc}
\hline Electrodes & $\boldsymbol{\lambda} \mathbf{( n m})$ & $\boldsymbol{T}_{\mathbf{o x}}$ & $\boldsymbol{T}_{\text {red }}$ & $\boldsymbol{\Delta} \boldsymbol{T}$ & $\boldsymbol{\Delta O D}$ & $\mathbf{Q}_{\boldsymbol{d}}\left(\mathbf{m C ~} \mathbf{c m}^{-\mathbf{2}}\right)$ & $\left.\boldsymbol{\eta} \mathbf{( c m}^{\mathbf{2}} \mathbf{C}^{-\mathbf{1}}\right)$ & $\boldsymbol{\tau}_{\mathbf{c}}(\mathbf{s})$ & $\boldsymbol{\tau}_{\mathbf{b}}(\mathbf{s})$ \\
\hline PDiCP & 1025 & 53.1 & 71.9 & 18.8 & 0.13 & 1.05 & 123.8 & 1.9 & 4.5 \\
P(DiCP-co-CPDT) & 1034 & 12.3 & 40.6 & 28.3 & 0.51 & 3.41 & 149.5 & 4.0 & 3.5 \\
P(DiCP-co-CPDT2) & 1034 & 4.6 & 33.7 & 29.1 & 0.86 & 10.63 & 80.9 & 6.7 & 3.9 \\
P(DiCP-co-CPDTK) & 1037 & 17.1 & 56.6 & 39.5 & 0.51 & 2.77 & 184.1 & 2.7 & 3.2 \\
P(DiCP-co-CPDTK2) & 890 & 38.2 & 74.1 & 35.9 & 0.28 & 2.51 & 111.5 & 1.9 & 2.4 \\
\hline
\end{tabular}

$\triangle \mathrm{OD}$ is the change of optical density, which can be calculated using the equation [39]:

$$
\Delta \mathrm{OD}=\log \left(\frac{T_{o x}}{T_{\text {red }}}\right)
$$

where $T_{\mathrm{ox}}$ and $T_{\text {red }}$ refer to the transmittance (\%) of oxidized and neutral states, respectively. The $\triangle \mathrm{OD}$ of PDiCP, P(DiCP-co-CPDT), P(DiCP-co-CPDT2), P(DiCP-co-CPDTK), and P(DiCP-co-CPDTK2) films at specific wavelengths in $0.2 \mathrm{M} \mathrm{LiClO}_{4} / \mathrm{ACN} / \mathrm{DCM}$ solution are listed in Table 3. P(DiCP-co-CPDT2) film shows the largest $\triangle \mathrm{OD}$ among these polymer films in $0.2 \mathrm{M} \mathrm{LiClO}_{4} / \mathrm{ACN} / \mathrm{DCM}$ solution.

Colouration efficiency $(\eta)$ is an important parameter for electrochromic materials and devices, and can be calculated using the formula [40]:

$$
\eta=\frac{\Delta \mathrm{OD}}{Q_{d}}
$$

where $Q_{\mathrm{d}}$ is the injected/ejected charge of the polymer films (or devices) per active area. Table 3 lists the $\eta$ of homopolymer and copolymer films in $0.2 \mathrm{M} \mathrm{LiClO}_{4} / \mathrm{ACN} / \mathrm{DCM}$ solution, the $\eta$ of PDiCP at $1025 \mathrm{~nm}, \mathrm{P}(\mathrm{DiCP}-\mathrm{co}-\mathrm{CPDT})$ at $1034 \mathrm{~nm}, \mathrm{P}(\mathrm{DiCP}-\mathrm{co}-\mathrm{CPDT} 2)$ at $1034 \mathrm{~nm}, \mathrm{P}(\mathrm{DiCP}-\mathrm{co}-\mathrm{CPDTK})$ at $1037 \mathrm{~nm}$, and $\mathrm{P}(\mathrm{DiCP}-\mathrm{co}-\mathrm{CPDTK} 2)$ at $890 \mathrm{~nm}$ are $123.8,149.5,80.9,184.1$, and $111.5 \mathrm{~cm}^{2} \mathrm{C}^{-1}$, respectively.

The comparisons of transmittance changes and colouration efficiencies with reported polymer films were displayed in Table 4, $\mathrm{P}(\mathrm{DiCP}-\mathrm{co}$-CPDTK) film showed higher transmittance change than those reported for PETCB film at $1100 \mathrm{~nm}$ [41], PMCzP film at $460 \mathrm{~nm}$ [42], and PBCz film at $1050 \mathrm{~nm}$ [43]. However, $\mathrm{P}(\mathrm{DiCP}-\mathrm{co}-\mathrm{CPDTK})$ film showed a lower transmittance change than those reported for $\mathrm{P}(\mathrm{BCz} 1-\mathrm{co}-\mathrm{Inc1})$ film at $787 \mathrm{~nm}[44]$ and $\mathrm{P}\left(\mathrm{NO}_{2}-3 \mathrm{Cz}\right)$ film at $710 \mathrm{~nm}$ [45]. On the other hand, $\mathrm{P}(\mathrm{DiCP}-c o-\mathrm{CPDTK})$ film revealed higher $\eta$ than those reported for $\mathrm{P}(\mathrm{BCz1}-c o-\operatorname{Inc1})$ [44], $\mathrm{P}\left(\mathrm{NO}_{2}-3 \mathrm{Cz}\right)$ [45], and $\mathrm{PBCz}$ films [43].

Table 4. Transmittance changes and colouration efficiencies of carbazole-based polymer films.

\begin{tabular}{cccc}
\hline Polymer Films & $\boldsymbol{\Delta} \boldsymbol{T}_{\max }(\mathbf{\%})$ & $\boldsymbol{\eta ( \mathrm { cm } ^ { \mathbf { 2 } } \mathbf { C } ^ { - \mathbf { 1 } } )}$ & Ref. \\
\hline PETCB & $36(1100 \mathrm{~nm})$ & - & 41 \\
PMCzP & $29(460 \mathrm{~nm})$ & - & 42 \\
PBCz & $18.6(1050 \mathrm{~nm})$ & 180.3 & 43 \\
P(BCz1-co-Inc1) & $43.0(787 \mathrm{~nm})$ & 148 & 44 \\
P(NO $-3 C z)$ & $52(710 \mathrm{~nm})$ & 35 & 45 \\
P(DiCP-co-CPDTK) & $39.5(1037 \mathrm{~nm})$ & 184.1 & This work \\
\hline
\end{tabular}

\subsection{Spectroelectrochemical Characterizations of Electrochromic Devices}

Five dual type ECDs based on PDiCP, P(DiCP-co-CPDT), P(DiCP-co-CPDT2), P(DiCP-co-CPDTK), and $\mathrm{P}(\mathrm{DiCP}-\mathrm{co}-\mathrm{CPDTK} 2)$ films as anodically-colouring polymers and PEDOT-PSS film as cathodically-colouring polymer were fabricated, which were denominated as PDiCP/PEDOT-PSS, P(DiCP-co-CPDT)/PEDOT-PSS, P(DiCP-co-CPDT2)/PEDOT-PSS, P(DiCP-co-CPDTK)/PEDOT-PSS, and $\mathrm{P}(\mathrm{DiCP}-\mathrm{co}-\mathrm{CPDTK} 2) / \mathrm{PEDOT}-\mathrm{PSS}$ ECDs, respectively. Figure 7a-e displayed the UV-VIS 
spectra of PDiCP/PEDOT-PSS, P(DiCP-co-CPDT)/PEDOT-PSS, P(DiCP-co-CPDT2)/PEDOT-PSS, $\mathrm{P}(\mathrm{DiCP}-c o-\mathrm{CPDTK}) / \mathrm{PEDOT}-\mathrm{PSS}$, and $\mathrm{P}(\mathrm{DiCP}-c o-\mathrm{CPDTK} 2) / \mathrm{PEDOT}-\mathrm{PSS}$ ECDs, respectively.
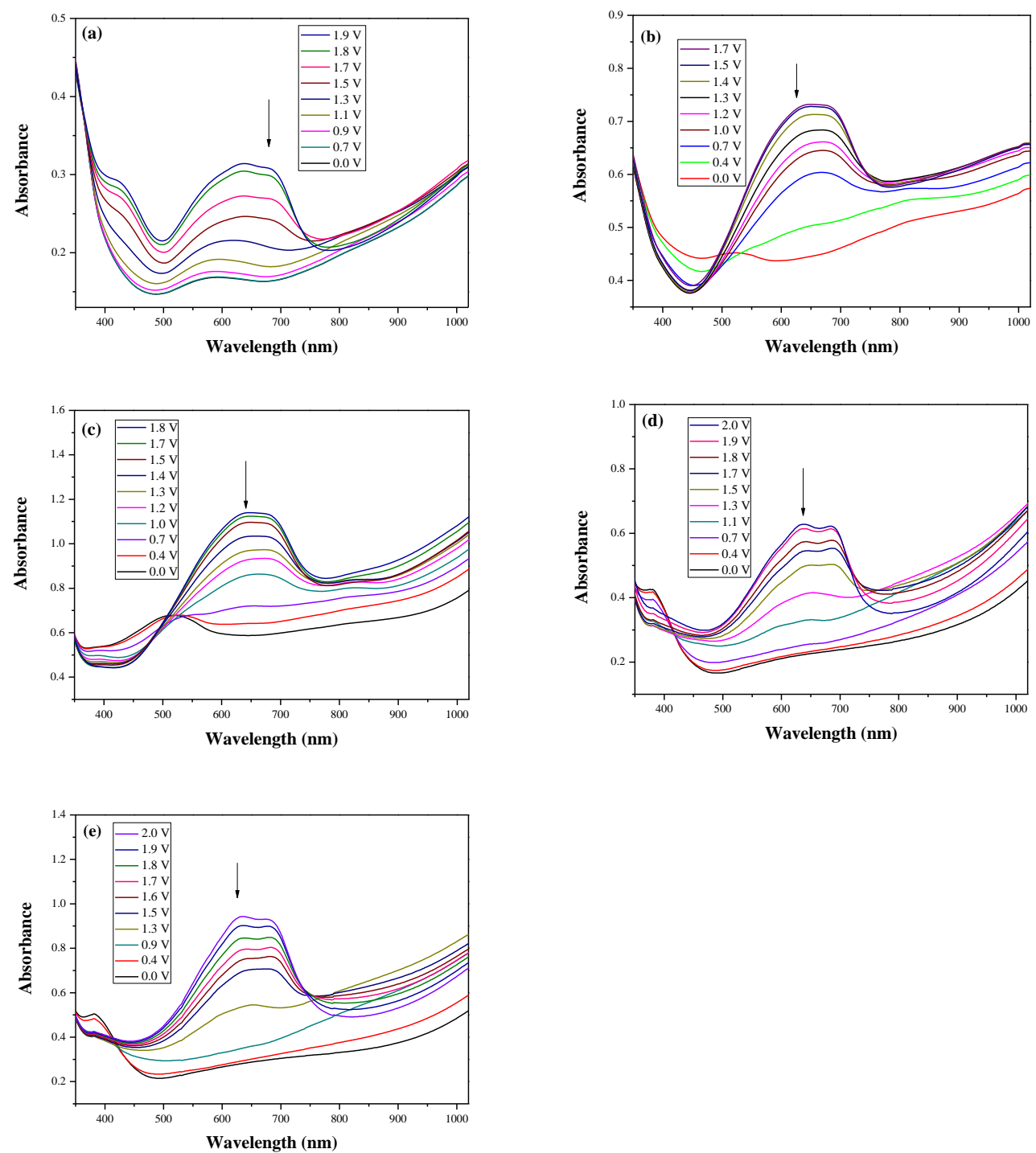

Figure 7. UV-VIS spectra of (a) PDiCP/PEDOT-PSS; (b) P(DiCP-co-CPDT)/PEDOT-PSS; (c) P(DiCP-co-CPDT2)/PEDOT-PSS; (d) P(DiCP-co-CPDTK)/PEDOT-PSS; and (e) P(DiCP-co-CPDTK2)/ PEDOT-PSS ECDs.

At $0.0 \mathrm{~V}$, PDiCP/PEDOT-PSS ECD did not show distinct absorption peaks in the ultraviolet and visible zones. At this moment, anodic PDiCP film was in its reduced state, displaying a light grey colour. The cathodic PEDOT-PSS film was in the oxidized state, displaying a limpid colour. Accordingly, the PDiCP/PEDOT-PSS ECD displayed light grey colour at $0.0 \mathrm{~V}$. Upon increasing the voltages gradually, PDiCP film started to oxidize and PEDOT-PSS film began to reduce. Accordingly, new peaks at 420 and $637 \mathrm{~nm}$ emerged gradually and the PDiCP/PEDOT-PSS ECD presented as dark blue at $1.9 \mathrm{~V}$. The main electrochromic response of PDiCP/PEDOT-PSS ECD comes from the PEDOT-PSS layer. Table 5 summarized the electrochromic photographs, colorimetric values $\left(L^{*}\right.$, $a^{*}$, and $\left.b^{*}\right)$ and CIE chromaticity diagrams of the P(DiCP-co-CPDTK)/PEDOT-PSS ECD at various potentials. $\mathrm{P}(\mathrm{DiCP}-\mathrm{co}$-CPDTK)/PEDOT-PSS ECD showed light silverish-yellow at $0.0 \mathrm{~V}$, light grey at $0.7 \mathrm{~V}$, grey at $1.3 \mathrm{~V}$, light greyish blue at $1.7 \mathrm{~V}$, and greyish blue at $2.0 \mathrm{~V}$. 
Table 5. Electrochromic photographs, colourimetric values $\left(L^{*}, a^{*}\right.$, and $\left.b^{*}\right)$, CIE chromaticity values $(x$, $y$ ), and CIE diagram of P(DiCP-co-CPDTK)/PEDOT-PSS ECD at various applied potentials.

\begin{tabular}{|c|c|c|c|c|c|c|c|}
\hline Potential (V) & Photographs & $L^{*}$ & $a^{*}$ & $b^{*}$ & $x$ & $y$ & Diagram \\
\hline 0.0 & & 81.81 & -3.79 & -0.90 & 0.43 & 0.41 & \\
\hline 0.7 & & 79.79 & -3.16 & -1.02 & 0.44 & 0.41 & \\
\hline 1.3 & & 68.79 & -10.12 & -10.64 & 0.41 & 0.40 & \\
\hline 1.7 & & 61.27 & -16.09 & -21.18 & 0.37 & 0.39 & \\
\hline 2.0 & & 55.36 & -19.91 & -29.70 & 0.34 & 0.38 & \\
\hline
\end{tabular}

Figure 8 showed the electrochromic switching profiles of PDiCP/PEDOT-PSS, P(DiCP-co-CPDT)/PEDOT-PSS, P(DiCP-co-CPDT2)/PEDOT-PSS, P(DiCP-co-CPDTK)/PEDOT-PSS, and $\mathrm{P}(\mathrm{DiCP}-\mathrm{co}-\mathrm{CPDTK} 2) / \mathrm{PEDOT}-\mathrm{PSS}$ ECDs, the transmittance variations of these ECDs were carried out between $0.0 \mathrm{~V}$ and $1.8 \mathrm{~V}$ with a time interval of $10 \mathrm{~s}$. The $\Delta T, \Delta \mathrm{OD}, Q_{\mathrm{d}}, \eta, \tau_{\mathrm{c}}$, and $\tau_{\mathrm{b}}$ of PDiCP/PEDOT-PSS, P(DiCP-co-CPDT)/PEDOT-PSS, P(DiCP-co-CPDT2)/PEDOT-PSS, $\mathrm{P}$ (DiCP-co-CPDTK)/PEDOT-PSS, and P(DiCP-co-CPDTK2)/PEDOT-PSS ECDs estimated the second cycle are listed in Table 6.
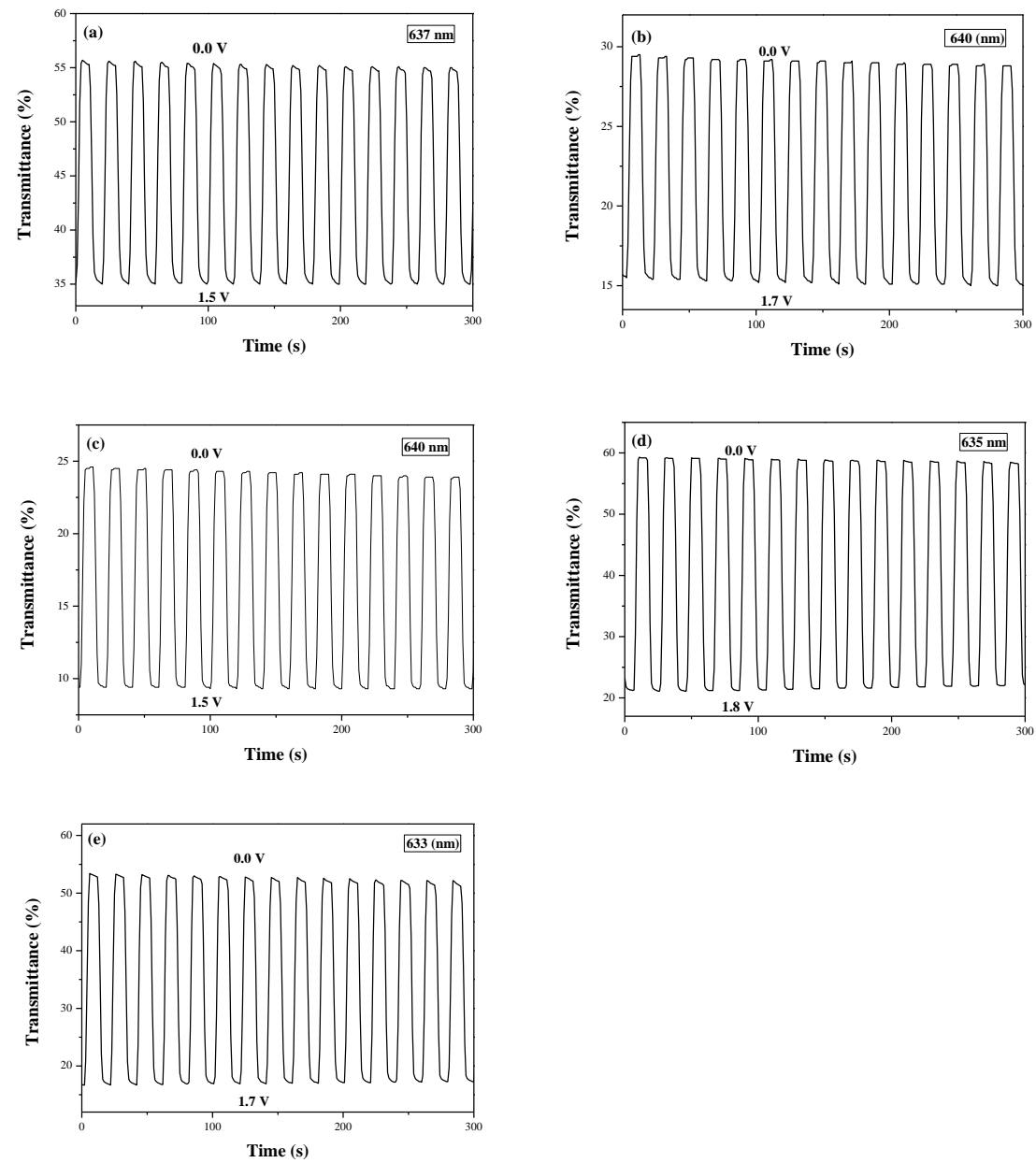

Figure 8. Optical contrast of (a) PDiCP/PEDOT-PSS; (b) P(DiCP-co-CPDT)/PEDOT-PSS; (c) P(DiCP-co-CPDT2)/PEDOT-PSS; (d) P(DiCP-co-CPDTK)/PEDOT-PSS; and (e) P(DiCP-co-CPDTK2)/ PEDOT-PSS ECDs with a residence time of $10 \mathrm{~s}$. 
Table 6. Optical and electrochemical properties investigated at the selected applied wavelength for the devices.

\begin{tabular}{|c|c|c|c|c|c|c|c|c|c|}
\hline Devices & $\lambda(\mathrm{nm})$ & $T_{\mathrm{ox}}$ & $T_{\text {red }}$ & $\Delta T$ & $\Delta \mathrm{OD}$ & $\mathrm{Q}_{d}\left(\mathrm{mC} \mathrm{cm}^{-2}\right)$ & $\eta\left(\mathrm{cm}^{2} \mathrm{C}^{-1}\right)$ & $\tau_{\mathrm{c}}(\mathrm{s})$ & $\tau_{\mathrm{b}}(\mathrm{s})$ \\
\hline PDiCP/PEDOT-PSS & 637 & 35.1 & 55.6 & 20.5 & 0.20 & 0.70 & 259.7 & 2.7 & 2.0 \\
\hline P(DiCP-co-CPDT)/PEDOT-PSS & 640 & 15.3 & 29.5 & 14.2 & 0.29 & 0.81 & 358.0 & 2.5 & 2.1 \\
\hline $\mathrm{P}$ (DiCP-co-CPDT2)/PEDOT-PSS & 640 & 9.4 & 24.7 & 15.3 & 0.42 & 0.91 & 461.5 & 2.6 & 2.7 \\
\hline P(DiCP-co-CPDTK)/PEDOT-PSS & 635 & 21.1 & 59.3 & 38.2 & 0.45 & 0.71 & 633.8 & 2.4 & 2.5 \\
\hline P(DiCP-co-CPDTK2)/PEDOT-PSS & 633 & 17.1 & 53.1 & 36.0 & 0.49 & 0.96 & 510.4 & 2.6 & 2.4 \\
\hline
\end{tabular}

$\mathrm{P}(\mathrm{DiCP}-\mathrm{co}-\mathrm{CPDTK}) / \mathrm{PEDOT}-\mathrm{PSS}$ and $\mathrm{P}(\mathrm{DiCP}-\mathrm{co}-\mathrm{CPDTK} 2) / \mathrm{PEDOT}-\mathrm{PSS}$ ECDs revealed larger $\Delta T$ than that of PDiCP/PEDOT-PSS ECD, whereas P(DiCP-co-CPDT)/PEDOT-PSS and $\mathrm{P}(\mathrm{DiCP}-\mathrm{co}-\mathrm{CPDT}$ )/PEDOT-PSS ECDs revealed smaller $\Delta T$ than that of PDiCP/PEDOT-PSS $\mathrm{ECD}$, implying the incorporation of $\mathrm{P}(\mathrm{DiCP}-c o-\mathrm{CPDTK})$ and $\mathrm{P}(\mathrm{DiCP}-\mathrm{co}-\mathrm{CPDTK} 2)$ as the anodically-colouring polymers led to a higher $\Delta T$ than those of PDiCP, $\mathrm{P}(\mathrm{DiCP}-c o-\mathrm{CPDT})$, and $\mathrm{P}(\mathrm{DiCP}-\mathrm{co}-\mathrm{CPDT}$ ) electrodes. In other aspects, the colouration efficiencies of PDiCP/PEDOT-PSS, P(DiCP-co-CPDT)/PEDOT-PSS, P(DiCP-co-CPDT2)/PEDOT-PSS, P(DiCP-co-CPDTK)/PEDOT-PSS, and P(DiCP-co-CPDTK2)/PEDOT-PSS ECDs were $259.7 \mathrm{mC} \mathrm{cm}^{-2}$ at $637 \mathrm{~nm}, 358.0 \mathrm{mC} \mathrm{cm}^{-2}$ at $640 \mathrm{~nm}$, $461.5 \mathrm{mC} \mathrm{cm}^{-2}$ at $640 \mathrm{~nm}, 633.8 \mathrm{mC} \mathrm{cm}^{-2}$ at $635 \mathrm{~nm}$, and $510.4 \mathrm{mC} \mathrm{cm}^{-2}$ at $633 \mathrm{~nm}$, respectively. The colouration efficiencies of $\mathrm{P}(\mathrm{DiCP}-\mathrm{co}-\mathrm{CPDT}) / \mathrm{PEDOT}-\mathrm{PSS}, \mathrm{P}(\mathrm{DiCP}-\mathrm{co}-\mathrm{CPDT}) / \mathrm{PEDOT}-\mathrm{PSS}$, $\mathrm{P}(\mathrm{DiCP}-\mathrm{co}-\mathrm{CPDTK}) / \mathrm{PEDOT}-\mathrm{PSS}$, and $\mathrm{P}(\mathrm{DiCP}-\mathrm{co}-\mathrm{CPDTK} 2) / \mathrm{PEDOT}-\mathrm{PSS}$ ECDs were greater than that of PDiCP/PEDOT-PSS ECD.

The comparisons of transmittance changes and colouration efficiencies with reported ECDs were displayed in Table 7, P(DiCP-co-CPDTK)/PEDOT-PSS ECD showed higher transmittance change than those reported for PtCz/PProDOT$\mathrm{Me}_{2}$ [46], poly(2,5-bis(9-methyl-9H-carbazol-3-yl)-1,3,4-oxadiazole)/PEDOT [47], poly(4,4'-di( $N$ carbazolyl)biphenyl)/PEDOT ECDs [48], and was comparable to those reported for

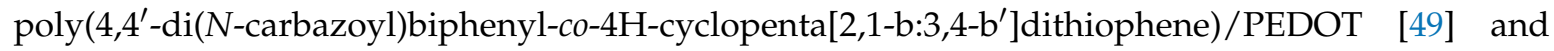
$\mathrm{P}(\mathrm{tnCz1}-\mathrm{co}-\mathrm{bTp} 2) / \mathrm{PProDOT}-\mathrm{Me}_{2}$ ECDs [50]. On the other side, P(DiCP-co-CPDTK)/PEDOT-PSS ECD revealed higher $\eta$ at $635 \mathrm{~nm}$ than those reported for $\mathrm{PtCz} / \mathrm{PProDOT}_{\mathrm{Me}}$ [46], poly (4,4'-di(N-carbazoyl)biphenyl-co-4H-cyclopenta[2,1-b:3,4-b']dithiophene)/PEDOT [49], and $\mathrm{P}$ (tnCz1-co-bTp2)/PProDOT-Me 2 ECDs [50], which made P(DiCP-co-CPDTK)/PEDOT-PSS ECD desirable for applications in rear-view mirrors of vehicles.

Table 7. Transmittance changes and colouration efficiencies of ECDs.

\begin{tabular}{|c|c|c|c|}
\hline ECD Configuration & $\Delta T_{\max }(\%)$ & $\eta_{\max }\left(\mathrm{cm}^{2} \mathrm{C}^{-1}\right)$ & Ref. \\
\hline $\mathrm{PtCz} /$ PProDOT-Me 2 & $36(572 \mathrm{~nm})$ & $343.4(572 \mathrm{~nm})$ & 46 \\
\hline poly(2,5-bis(9-methyl-9H-carbazol-3-yl)-1,3,4-oxadiazole)/PEDOT & $35(620 \mathrm{~nm})$ & - & 47 \\
\hline poly $\left(4,4^{\prime}\right.$-di(N-carbazolyl)biphenyl)/PEDOT & $19(550 \mathrm{~nm})$ & - & 48 \\
\hline 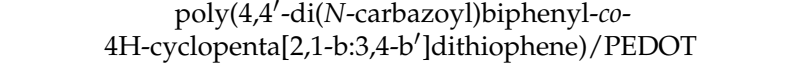 & $39.8(628 \mathrm{~nm})$ & $319.98(628 \mathrm{~nm})$ & 49 \\
\hline $\mathrm{P}(\mathrm{tnCz} 1-c o-b T \mathrm{p} 2) / \mathrm{PProDOT}_{-} \mathrm{Me}_{2}$ & $40(630 \mathrm{~nm})$ & $519(630 \mathrm{~nm})$ & 50 \\
\hline P(DiCP-co-CPDTK)/PEDOT-PSS & $38.2(635 \mathrm{~nm})$ & $634(635 \mathrm{~nm})$ & This work \\
\hline
\end{tabular}

\subsection{Optical Memory of ECDs}

The ability to maintain a bleached (or coloured) state at open circuit of PDiCP/PEDOT-PSS, P(DiCP-co-CPDT)/PEDOT-PSS, P(DiCP-co-CPDT2)/PEDOT-PSS, P(DiCP-co-CPDTK)/PEDOT-PSS, and $\mathrm{P}(\mathrm{DiCP}-\mathrm{co}-\mathrm{CPDTK} 2) / \mathrm{PEDOT}-\mathrm{PSS}$ ECDs was measured in bleached and coloured states by applying a potential for $1 \mathrm{~s}$ in a time interval of each $100 \mathrm{~s}$ [51]. As shown in Figure 9, the PDiCP/PEDOT-PSS, P(DiCP-co-CPDT)/PEDOT-PSS, P(DiCP-co-CPDT2)/PEDOT-PSS, $\mathrm{P}(\mathrm{DiCP}-\mathrm{co}$-CPDTK)/PEDOT-PSS, and P(DiCP-co-CPDTK2)/PEDOT-PSS ECDs showed almost no transmittance change in bleached state, displaying satisfactory optical memories in bleached state. However, ECDs were rather less stable than those in the bleached state, but the 
transmittance variations were less than $4 \%$ in the coloured state, indicating the PDiCP/PEDOT-PSS, P(DiCP-co-CPDT)/PEDOT-PSS, P(DiCP-co-CPDT2)/PEDOT-PSS, P(DiCP-co-CPDTK)/PEDOT-PSS, and $\mathrm{P}(\mathrm{DiCP}-\mathrm{co}-\mathrm{CPDTK} 2) / \mathrm{PEDOT}-\mathrm{PSS}$ ECDs had desirable optical memories.
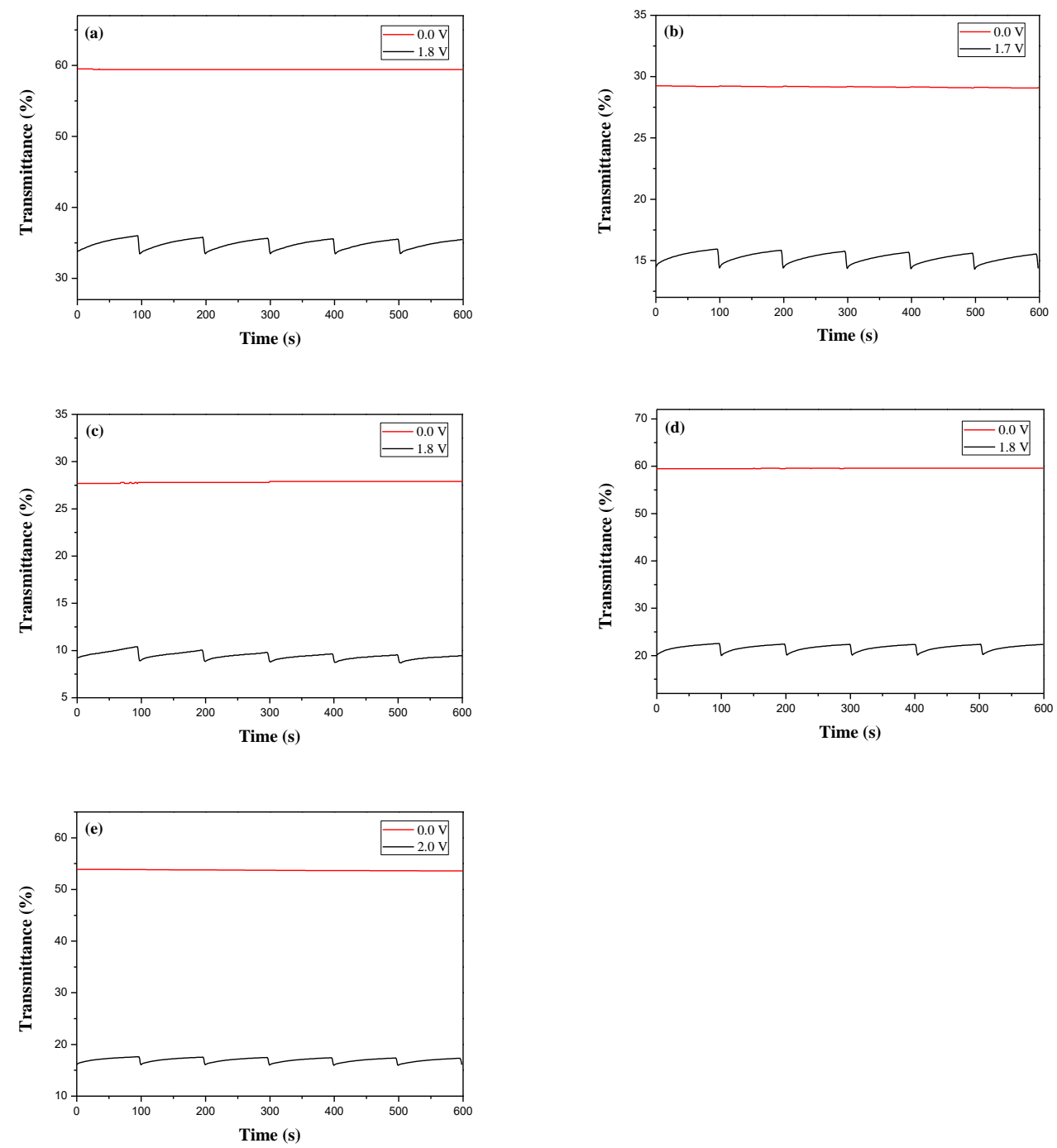

Figure 9. Open circuit stability of (a) PDiCP/PEDOT-PSS; (b) P(DiCP-co-CPDT)/PEDOT-PSS; (c) P(DiCP-co-CPDT2)/PEDOT-PSS; (d) P(DiCP-co-CPDTK)/PEDOT-PSS; and (e) P(DiCP-co-CPDTK2)/ PEDOT-PSS devices.

\subsection{Redox Stability of ECDs}

The multiple switching stability of PDiCP/PEDOT-PSS, P(DiCP-co-CPDT2)/PEDOT-PSS, and $\mathrm{P}$ (DiCP-co-CPDTK)/PEDOT-PSS ECDs was monitored using CV at potentials between 0.0 and $1.8 \mathrm{~V}$ with a scan rate of $500 \mathrm{mV} \mathrm{s}^{-1}$ as displayed in Figure 10 [52]. Electrochemical activity of $89.0 \%, 87.2 \%$, and $92.4 \%$ was preserved after 500 cycles, respectively, and $81.2 \%$, $86.6 \%$, and $88.8 \%$, respectively, of electrochemical activity was preserved after 1000 cycles for PDiCP/PEDOT-PSS, P(DiCP-co-CPDT2)/PEDOT-PSS, and P(DiCP-co-CPDTK)/PEDOT-PSS ECDs. P(DiCP-co-CPDT2)/PEDOT-PSS and P(DiCP-co-CPDTK)/PEDOT-PSS ECDs employed copolymers as anodic electrodes presented better multiple cycling stability than that of PDiCP (homopolymer)/PEDOT-PSS ECD. Considering the above consequences, these ECDs displayed adequate redox stability for electrochromic applications. 

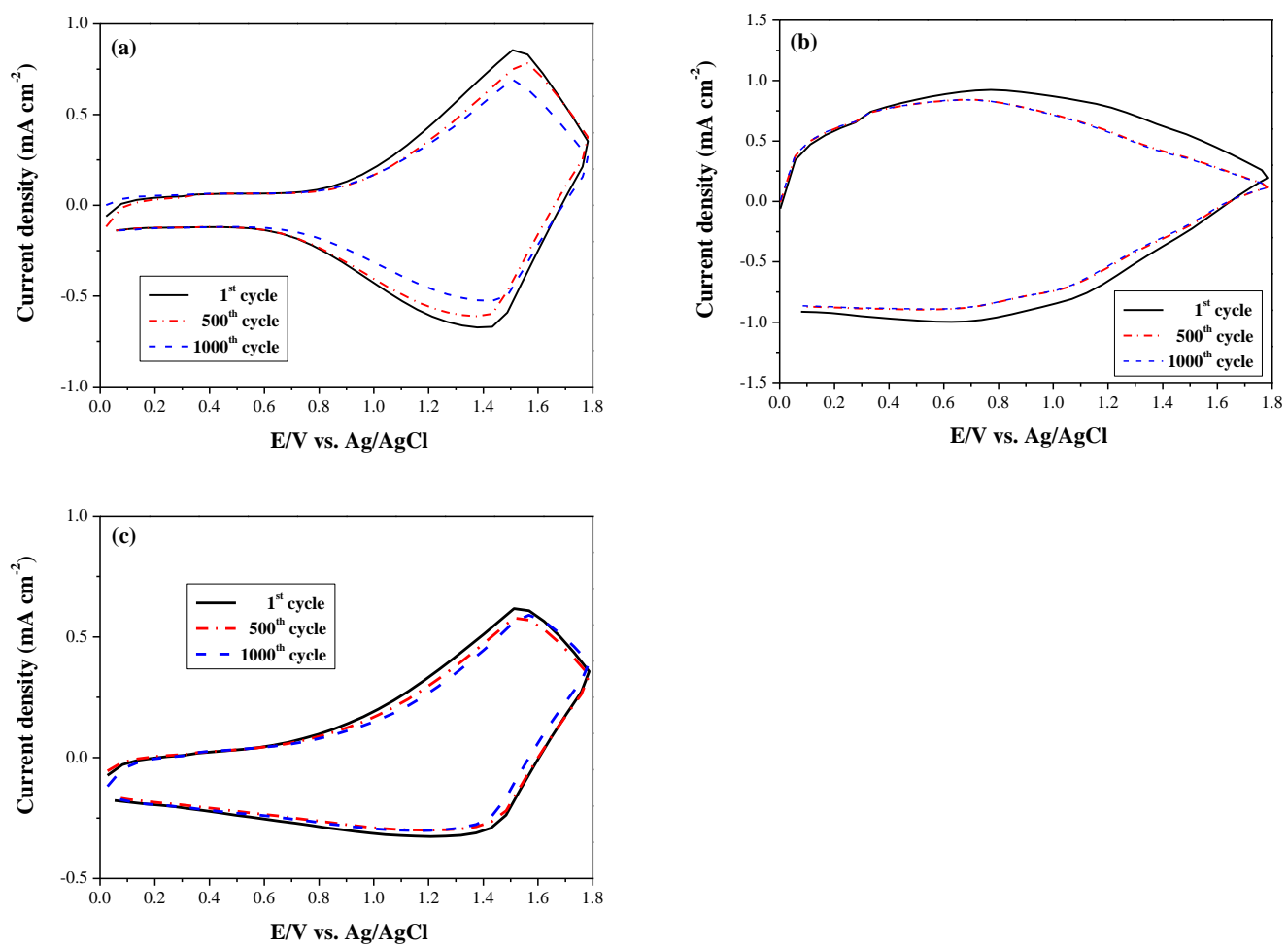

Figure 10. Cyclic voltammograms of (a) PDiCP/PEDOT-PSS; (b) P(DiCP-co-CPDT2)/PEDOT-PSS; and (c) $\mathrm{P}$ (DiCP-co-CPDTK)/PEDOT-PSS devices with a scan rate of $500 \mathrm{mV} \mathrm{s}^{-1}$ at the first, $500^{\text {th }}$, and $1000^{\text {th }}$ cycles.

\section{Conclusions}

An anodic homopolymer (PDiCP) and four copolymers (P(DiCP-co-CPDT), P(DiCP-co-CPDT2), $\mathrm{P}(\mathrm{DiCP}-\mathrm{co}-\mathrm{CPDTK})$, and $\mathrm{P}(\mathrm{DiCP}-\mathrm{co}-\mathrm{CPDTK} 2))$ were prepared electrochemically. PDiCP homopolymer film was light grey in the neutral state, dark khaki in the intermediate state, and grey black in the oxidized states. For the copolymer films, $\mathrm{P}(\mathrm{DiCP}-\mathrm{co}-\mathrm{CPDT})$ and $\mathrm{P}(\mathrm{DiCP}-\mathrm{co}-\mathrm{CPDT} 2)$ films were light brown at $0.0 \mathrm{~V}$, light cadet blue at $0.4 \mathrm{~V}$, and navy blue at 1.2 (or $1.3 \mathrm{~V}$ ), whereas $\mathrm{P}(\mathrm{DiCP}$-co-CPDTK) and $\mathrm{P}(\mathrm{DiCP}-\mathrm{co}-\mathrm{CPDTK} 2)$ films were light yellow at $0.0 \mathrm{~V}$, grey at $0.8 \mathrm{~V}$, and rock grey at $1.1 \mathrm{~V}$. Electrochromic switching characterizations of anodically-colouring polymers revealed high $\Delta T$ and $\eta$ for P(DiCP-co-CPDTK) film, which were determined as $39.5 \%$ and $184.1 \mathrm{~cm}^{2} \mathrm{C}^{-1}$ at 1037 $\mathrm{nm}$, respectively. Five dual-type ECDs based on PDiCP, P(DiCP-co-CPDT), P(DiCP-co-CPDT2), $\mathrm{P}(\mathrm{DiCP}-\mathrm{co}$-CPDTK), and $\mathrm{P}(\mathrm{DiCP}-c o-\mathrm{CPDTK} 2)$ films as anodically-colouring polymers and PEDOT-PSS film as cathodically-colouring polymer were fabricated and their spectroelectrochemical properties were characterized. $\mathrm{P}(\mathrm{DiCP}-\mathrm{co}-\mathrm{CPDTK}) / \mathrm{PEDOT}-\mathrm{PSS}$ ECD revealed light silverish-yellow, light grey, grey, light greyish blue, and greyish blue at $0.0 \mathrm{~V}, 0.7 \mathrm{~V}, 1.3 \mathrm{~V}, 1.7 \mathrm{~V}$, and $2.0 \mathrm{~V}$, respectively. $\mathrm{P}$ (DiCP-co-CPDTK)/PEDOT-PSS and $\mathrm{P}(\mathrm{DiCP}-\mathrm{co}$-CPDTK2)/PEDOT-PSS ECDs showed high $\Delta T$ (38.2\% and 36.0\% for P(DiCP-co-CPDTK)/PEDOT-PSS and P(DiCP-co-CPDTK2)/PEDOT-PSS ECDs, respectively), high $\eta$ (633.8 and $510.4 \mathrm{mC} \mathrm{cm}^{-2}$ for $\mathrm{P}(\mathrm{DiCP}-c o-C P D T K) / P E D O T-P S S$ and $\mathrm{P}(\mathrm{DiCP}-\mathrm{co}-\mathrm{CPDTK} 2) / \mathrm{PEDOT}-\mathrm{PSS}$ ECDs, respectively), and high $\triangle \mathrm{OD}$ values. In addition, $\mathrm{P}(\mathrm{DiCP}-\mathrm{co}-\mathrm{CPDTK}) / \mathrm{PEDOT}-\mathrm{PSS}$ displayed suitable redox stability and optical memory.

Author Contributions: C.-W.K. conceived the research topic. B.-W.W. and T.-Y.W. carried out the experiments. C.-W.K., T.-Y.W., J.-C.C., L.-T.L., J.-K.C., and T.-H.H. analysed the electrochromic properties.

Acknowledgments: The authors thank the Ministry of Science and Technology of Republic of China for financially supporting this project.

Conflicts of Interest: The authors declare no conflict of interest. 


\section{References}

1. Ding, Y.; Zhang, C.; Zhang, L.; Zhou, Y.; Yu, G. Molecular engineering of organic electroactive materials for redox flow batteries. Chem. Soc. Rev. 2018, 47, 69-103. [CrossRef] [PubMed]

2. Fu, W.C.; Hsieh, Y.T.; Wu, T.Y.; Sun, I.W. Electrochemical preparation of porous poly(3,4ethylenedioxythiophene) electrodes from room temperature ionic liquids for supercapacitors. J. Electrochem. Soc. 2016, 163, G61-G68. [CrossRef]

3. Wu, T.Y.; Chen, Y. Synthesis, optical and electrochemical properties of novel copolymers containing alternate 2,3-quinoxaline and hole-transporting units. J. Polym. Sci. Part A Polym. Chem. 2002, 40, 4570-4580. [CrossRef]

4. Al-Asbahi, B.A.; Haji Jumali, M.H.; AlSalhi, M.S. Enhanced optoelectronic properties of PFO/fluorol 7GA hybrid light emitting diodes via additions of $\mathrm{TiO}_{2}$ nanoparticles. Polymers 2016, 8, 334. [CrossRef]

5. Wu, T.Y.; Chen, Y. Synthesis and characterization of novel luminescent polymers with alternate phenothiazine and divinylbenzene units. J. Polym. Sci. Part A Polym. Chem. 2002, 40, 4452-4462. [CrossRef]

6. Hsiao, S.-H.; Liao, Y.-C. Facile synthesis of electroactive and electrochromic triptycene poly(ether-imide)s containing triarylamine units via oxidative electro-coupling. Polymers 2017, 9, 497. [CrossRef]

7. Sato, K.; Mizukami, R.; Mizuma, T.; Nishide, H.; Oyaizu, K. Synthesis of dimethyl-substituted polyviologen and control of charge transport in electrodes for high-resolution electrochromic displays. Polymers 2017, 9, 86. [CrossRef]

8. Hacioglu, S.O.; Yiğit, D.; Ermis, E.; Soylemez, S.; Güllü, M.; Toppare, L. Syntheses and electrochemical characterization of low oxidation potential nitrogen analogs of pedot as electrochromic materials. J. Electrochem. Soc. 2016, 163, E293-E299. [CrossRef]

9. Wang, R.; Yan, X.; Yang, X.; Wang, Y.; Li, H.; Sheng, C. Long lived photoexcitation dynamics in $\pi$-conjugated polymer/PbS quantum dot blended films for photovoltaic application. Polymers 2017, 9, 352. [CrossRef]

10. Raja, R.; Luo, S.; Hsiow, C.-Y.; Rwei, S.-P.; Wang, L. Novel two-dimensional conjugated polymer containing fluorinated bithiophene as donor and benzoselenodiazole as acceptor units with vinyl-terthiophene pendants for polymer photovoltaic cells. Polymers 2017, 9, 272. [CrossRef]

11. Wu, T.Y.; Sheu, R.B.; Chen, Y. Synthesis, optically acid-sensory and electrochemical properties of novel polyoxadiazole derivatives. Macromolecules 2004, 37, 725-733. [CrossRef]

12. Wu, T.Y.; Chen, Y. Poly(phenylene vinylene)-based copolymers containing 3,7-phenothiazylene and 2,6-pyridylene chromophores: Fluorescence sensors for acids, metal ions, and oxidation. J. Polym. Sci. Part A Polym. Chem. 2004, 42, 1272-1284. [CrossRef]

13. Wu, T.Y.; Kuo, C.W.; Chen, Y.L.; Chang, J.K. Copolymers based on indole-6-carboxylic acid and 3,4-ethylenedioxythiophene as platinum catalyst support for methanol oxidation. Catalysts 2015, 5, 1657-1672. [CrossRef]

14. Kuo, C.W.; Chen, S.J.; Chen, P.R.; Tsai, W.T.; Wu, T.Y. Doping process effect of polyaniline doped with poly(styrenesulfonic acid) supported platinum for methanol oxidation. J. Taiwan Inst. Chem. Eng. 2013, 44, 497-504. [CrossRef]

15. Wu, T.Y.; Chen, B.K.; Chang, J.K.; Chen, P.R.; Kuo, C.W. Nanostructured poly(aniline-co-metanilic acid) as platinum catalyst support for electro-oxidation of methanol. Int. J. Hydrog. Energy 2015, 40, 2631-2640. [CrossRef]

16. Horowitz, G. Organic Field-Effect Transistors. Adv. Mater. 1998, 10, 365-377. [CrossRef]

17. Hsiao, S.H.; Chiu, Y.T. Electrosynthesis and electrochromic properties of poly(amide-triarylamine)s containing triptycene units. RSC Adv. 2015, 5, 90941-90951. [CrossRef]

18. Liu, J.; Mi, S.; Xu, Z.; Wu, J.; Zheng, J.; Xu, C. Solution-processable thiophene-based electrochromic polymers bearing trifluoromethyl rather than long side chains. Org. Electron. 2016, 37, 169-177. [CrossRef]

19. Su, Y.-S.; Wu, T.-Y. Three carbazole-based polymers as potential anodically coloring materials for high-contrast electrochromic devices. Polymers 2017, 9, 284. [CrossRef]

20. Hsiao, S.H.; Wu, L.C. Fluorescent and electrochromic polymers from 2,8-di(carbazol-9-yl)dibenzothiophene and its $S, S$-dioxide derivative. Dyes Pigments 2016, 134, 51-63. [CrossRef]

21. Lu, Q.; Cai, W.; Niu, H.; Wang, W.; Bai, X.; Hou, Y. Novel polyamides with 5H-dibenzo[b,f]azepin5-yl-substituted triphenylamine: Synthesis and visible-NIR electrochromic properties. Polymers 2017, 9, 542. [CrossRef] 
22. Hsiao, S.-H.; Lu, H.-Y. Electrosynthesis of aromatic poly(amide-amine) films from triphenylamine-based electroactive compounds for electrochromic applications. Polymers 2017, 9, 708. [CrossRef]

23. Wu, T.Y.; Li, W.B.; Kuo, C.W.; Chou, C.F.; Liao, J.W.; Chen, H.R.; Tseng, C.G. Study of poly(methyl methacrylate)-based gel electrolyte for electrochromic device. Int. J. Electrochem. Sci. 2013, 8, 10720-10732.

24. Kuo, C.-W.; Wu, T.-Y.; Fan, S.-C. Applications of poly(indole-6-carboxylic acid-co-2,2'-bithiophene) films in high-contrast electrochromic devices. Coatings 2018, 8, 102. [CrossRef]

25. Kuo, C.W.; Hsieh, T.H.; Hsieh, C.K.; Liao, J.W.; Wu, T.Y. Electrosynthesis and characterization of four electrochromic polymers based on carbazole and indole-6-carboxylic acid and their applications in high-contrast electrochromic devices. J. Electrochem. Soc. 2014, 161, D782-D790. [CrossRef]

26. Ding, G.; Cho, C.M.; Chen, C.; Zhou, D.; Wang, X.; Tan, A.Y.X.; Xu, J.; Lu, X. Black-to-transmissive electrochromism of azulene-based donor-acceptor copolymers complemented by poly(4-styrene sulfonic acid)-doped poly(3,4-ethylenedioxythiophene). Org. Electron. 2013, 14, 2748-2755. [CrossRef]

27. Hsiao, S.-H.; Liao, W.-K.; Liou, G.-S. Synthesis and electrochromism of highly organosoluble polyamides and polyimides with bulky trityl-substituted triphenylamine units. Polymers 2017, 9, 511. [CrossRef]

28. Guzel, M.; Soganci, T.; Akgun, M.; Ak, M. Carbazole functionalized star shaped triazine monomer and its electrochromic applications. J. Electrochem. Soc. 2015, 162, H527-H534. [CrossRef]

29. Ouyang, M.; Fu, Z.; Lv, X.; Hu, B.; Wang, P.; Huang, S.; Dai, Y.; Zhang, C. A multichromic copolymer based on 4-(9H-carbazol-9-yl)- $N, N$-diphenylaniline and 3,4-ethylenedioxythiophene prepared via electrocopolymerization. J. Electrochem. Soc. 2013, 160, H787-H792. [CrossRef]

30. Su, Y.S.; Chang, J.C.; Wu, T.Y. Applications of three dithienylpyrroles-based electrochromic polymers in high-contrast electrochromic devices. Polymers 2017, 9, 114. [CrossRef]

31. Kuo, C.W.; Chen, B.K.; Li, W.B.; Tseng, L.Y.; Wu, T.Y.; Tseng, C.G.; Chen, H.R.; Huang, Y.C. Effects of supporting electrolytes on spectroelectrochemical and electrochromic properties of polyaniline-poly(styrene sulfonic acid) and poly(ethylenedioxythiophene)-poly(styrene sulfonic acid)-based electrochromic device. J. Chin. Chem. Soc. 2014, 61, 563-570. [CrossRef]

32. Chang, K.H.; Wang, H.P.; Wu, T.Y.; Sun, I.W. Optical and electrochromic characterizations of four 2,5-dithienylpyrrole-based conducting polymer films. Electrochim. Acta 2014, 119, 225-235. [CrossRef]

33. Carbas, B.B.; Kivrak, A.; Teke, E.; Zora, M.; Önal, A.M. Electrochemical polymerization of a new low-voltage oxidized thienylenepyrrole derivative and its electrochromic device application. J. Electroanal. Chem. 2014, 729, 15-20. [CrossRef]

34. Soganci, T.; Soyleyici, H.C.; Ak, M.; Cetisli, H. An amide substituted dithienylpyrrole based copolymer: Its electrochromic properties physical and analytical electrochemistry, electrocatalysis, and photoelectrochemistry. J. Electrochem. Soc. 2016, 163, H59-H66. [CrossRef]

35. Wu, T.Y.; Tsao, M.H.; Chen, F.L.; Su, S.G.; Chang, C.W.; Wang, H.P.; Lin, Y.C.; Ou-Yang, W.C.; Sun, I.W. Synthesis and characterization of organic dyes containing various donors and acceptors. Int. J. Mol. Sci. 2010, 11, 329-353. [CrossRef] [PubMed]

36. Tsao, M.H.; Wu, T.Y.; Wang, H.P.; Sun, I.W.; Su, S.G.; Lin, Y.C.; Chang, C.W. An efficient metal free sensitizer for dye-sensitized solar cells. Mater. Lett. 2011, 65, 583-586. [CrossRef]

37. Wu, T.Y.; Chen, Y. Synthesis and characterization of luminescent copolymers containing iminodibenzyl and divinylbenzene chromophores. J. Polym. Sci. Part A Polym. Chem. 2002, 40, 3847-3857. [CrossRef]

38. Chen, Y.; Wu, T.Y. Synthesis, optical and electrochemical properties of luminescent copolymers containing N-hexyl-3,8-iminodibenzyl chromophores. Polymer 2001, 42, 9895-9901. [CrossRef]

39. Wu, T.Y.; Li, J.L. Electrochemical synthesis, optical, electrochemical and electrochromic characterizations of indene and 1,2,5-thiadiazole-based poly(2,5-dithienylpyrrole) derivatives. RSC Adv. 2016, 6, 15988-15998. [CrossRef]

40. Wu, T.-Y.; Chung, H.-H. Applications of tris(4-(thiophen-2-yl)phenyl)amine- and dithienylpyrrole-based conjugated copolymers in high-contrast electrochromic devices. Polymers 2016, 8, 206. [CrossRef]

41. Hu, B.; Lv, X.; Sun, J.; Bian, G.; Ouyang, M.; Fu, Z.; Wang, P.; Zhang, C. Effects on the electrochemical and electrochromic properties of 3,6 linked polycarbazole derivative by the introduction of different acceptor groups and copolymerization. Org. Electron. 2013, 14, 1521-1530. [CrossRef]

42. Wang, B.; Zhao, J.; Xiao, J.; Cui, C.; Liu, R. Synthesis and electropolymerization of 9H-carbazol-9-ylpyrene and its electrochromic properties and electrochromic device application. Int. J. Electrochem. Sci. 2012, 7, 2781-2795. 
43. Kuo, C.-W.; Wu, T.-L.; Lin, Y.-C.; Chang, J.-K.; Chen, H.-R.; Wu, T.-Y. Copolymers based on 1,3bis(carbazol-9-yl)benzene and three 3,4-ethylenedioxythiophene derivatives as potential anodically coloring copolymers in high-contrast electrochromic devices. Polymers 2016, 8, 368. [CrossRef]

44. Kuo, C.W.; Wu, T.Y.; Huang, M.W. Electrochromic characterizations of copolymers based on 4,4'-bis( $N$-carbazolyl)-1,1'-biphenyl and indole-6-carboxylic acid and their applications in electrochromic devices. J. Taiwan Inst. Chem. Eng. 2016, 68, 481-488. [CrossRef]

45. Hsiao, S.H.; Lin, S.W. Electrochemical synthesis of electrochromic polycarbazole films from $N$-phenyl-3,6-bis(N-carbazolyl)carbazoles. Polym. Chem. 2016, 7, 198-211. [CrossRef]

46. Kuo, C.W.; Chang, J.K.; Lin, Y.C.; Wu, T.Y.; Lee, P.Y.; Ho, T.H. Poly(tris(4-carbazoyl-9-ylphenyl)amine)/three poly(3,4-ethylenedioxythiophene) derivatives complementary high-contrast electrochromic devices. Polymers 2017, 9, 543. [CrossRef]

47. Udum, Y.A.; Gündoğdu Hızlıateş, C.; Ergün, Y.; Toppare, L. Electrosynthesis and characterization of an electrochromic material containing biscarbazole-oxadiazole units and its application in an electrochromic device. Thin Solid Films 2015, 595, 61-67. [CrossRef]

48. Koyuncu, S.; Gultekin, B.; Zafer, C.; Bilgili, H.; Can, M.; Demic, S.; Kaya, I.; Icli, S. Electrochemical and optical properties of biphenyl bridged-dicarbazole oligomer films: Electropolymerization and electrochromism. Electrochim. Acta 2009, 54, 5694-5702. [CrossRef]

49. Chen, S.; Gao, Q.; Zhao, J.; Cui, C.; Yang, W.; Zhang, X. Electrosyntheses, characterizations and electrochromic properties of a novel copolymer of 4,4'-di(N-carbazoyl)biphenyl with $4 \mathrm{H}$-cyclopenta[2,1-b:3,4- $\mathrm{b}^{\prime}$ ]dithiophene. Int. J. Electrochem. Sci. 2012, 7, 5256-5272.

50. Kuo, C.-W.; Lee, P.-Y. Electrosynthesis of copolymers based on 1,3,5-tris( $N$-carbazolyl)benzene and 2,2'-bithiophene and their applications in electrochromic devices. Polymers 2017, 9, 518. [CrossRef]

51. Wu, T.Y.; Su, Y.S. Electrochemical synthesis and characterization of 1,4-benzodioxan-based electrochromic polymer and its application in electrochromic devices. J. Electrochem. Soc. 2015, 162, G103-G112. [CrossRef]

52. Wu, T.Y.; Liao, J.W.; Chen, C.Y. Electrochemical synthesis, characterization and electrochromic properties of indan and 1,3-benzodioxole-based poly(2,5-dithienylpyrrole) derivatives. Electrochim. Acta 2014, 150, 245-262. [CrossRef] 